\title{
¿Es posible la integración residencial en las ciudades chilenas? Disposición de los grupos medios y altos a la integración con grupos de extracción popular
}

Francisco Sabatini. Pontificia Universidad Católica de Chile, Santiago, Chile.

Alejandra Rasse. Universidad Católica del Maule, Talca, Chile.

Pía Mora. Pontificia Universidad Católica de Chile, Santiago, Chile.

Isabel Brain. Pontificia Universidad Católica de Chile, Santiago, Chile.

RESUMEN | Con relativa independencia de su nivel social, edad y sexo, los residentes de las ciudades chilenas de Santiago, Antofagasta y Temuco muestran una significativa disposición a la integración residencial con personas de otra condición social. Sin embargo, dicha valoración de la integración enfrenta, por una parte, obstáculos y temores concretos (como el menoscabo a las plusvalías o respecto de la formación de los hijos) que dificultan que se materialice en barrios menos segregados; y por otra, actitudes y conductas "clasistas". En términos prácticos, esta cultura urbana tensionada y ambivalente, junto a la relativa asimetría que presenta la segregación residencial entre sus dimensiones principales en el medio latinoamericano y a la prevalencia de una mezcla de indiferencia y tolerancia en la relación con el "otro", propia de las ciudades modernas, otorgarían viabilidad cultural a futuras políticas de reducción de la segregación.

PALABRAS CLAVE | Segregación, cultura urbana, integración social

\begin{abstract}
With relative independence of their social level, age or sex, the residents of the Chilean cities of Santiago, Antofagasta and Temuco show a significant disposition to residential integration with people of different social conditions. However, this positive evaluation of integration is confronted by concrete obstacles and fears (like the possible damage to the value of their properties or to the education of their children) that make the materialization of less segregated neighborhoods harder, on the one hand, and "classist" attitudes and conducts, on the other. In practical terms, this ambivalent urban culture, together with a relative assymetry of residential segregation are the main dimensions in the Latin American context. These, together with a mixture of indifference and tolerance towards the "other", which are characteristic of modern cities, give cultural viability to future policies for the reduction of segregation.
\end{abstract}

KEY WORDS | Segregation, urban culture, social integration

Recibido el 19 de mayo de 2011, aprobado el 31 de agosto de 2011

E-mail: Francisco Sabatini, fsabatin@uc.cl | Alejandra Rasse, arasse@ucm.cl | Pía Mora, mimora@uc.cl | Isabel Brain, ibrain@uc.cl

El presente artículo se basa en dos investigaciones empíricas realizadas en los últimos años: i) el estudio "Disposición a la integración social urbana en Santiago, Antofagasta y Temuco: Una mirada desde la integración residencial”, realizado en 2008, por ProUrbana-Pontificia Universidad Católica de Chile (PUC) y el Observatorio Social-Universidad Alberto Hurtado (UAH), para el Ministerio de Vivienda y Urbanismo, Chile; y ii) la investigación "Cultura de integración y cohesión social en las ciudades chilenas", que corresponde a un estudio aún en desarrollo iniciado el año 2009, encabezado por los institutos de Sociología y de Estudios Urbanos (PUC), y que se inserta en el Programa Bicentenario en Ciencia y Tecnología-Comisión Nacional de Investigación Científica y Tecnológica (Conicyt, Chile). 


\section{Introducción}

El interés por comprender la disposición a la integración residencial surge, primero, de la comprobación de los nocivos efectos que la segregación residencial, en su dimensión de homogeneidad en pobreza, genera para las aspiraciones y trayectorias de movilidad social ascendente de los hogares de menores recursos; y en segundo término, del interés por indagar qué espacio o voluntad existe en la ciudadanía y la población urbana chilena para atacar este fenómeno, y bajo qué condiciones.

El punto de partida de este artículo es la constatación de la significativa distancia que existe entre la elevada disposición a la integración residencial declarada por los residentes de ciudades chilenas y la disposición observada o concreta, que es mucho menor. El declive entre aquello que se dice y lo que se hace cuando se trata de integración residencial puede ser atribuido a factores que obstaculizan la posibilidad de que personas de distinta condición social vivan próximas, factores que pueden ser clasificados en trabas culturales y en otras de tipo estructural, principalmente económicas y funcionales.

En este trabajo evaluamos el peso que tendrían uno y otro tipo de trabas. Nuestra hipótesis, basada en la observación de datos, es que en la determinación de las conductas en materia de integración pesarían más los factores estructurales que los culturales. Vale decir, nuestra cultura no sería el principal impedimento para alcanzar mayores niveles de integración.

Desde la cultura se argumenta que la proximidad física entre personas de distinta condición social no es posible, debido a que somos profundamente clasistas. Sin embargo, en el peor de los escenarios - es decir, en el de un clasismo extendido y coherente-, la proximidad residencial no es imposible: la convivencia en el espacio por parte de personas diferentes puede darse bajo un patrón verticalista. De hecho, tradicionalmente en nuestro país muchos espacios han albergado la diversidad social respetando un orden jerárquico. Desde otra mirada (a la que adherimos con más entusiasmo, aunque sin descartar de plano la visión más pesimista recién expuesta), el clasismo existente convive con otras capas de significado, otros valores e ideas que están penetrando nuestra sociedad: la cultura ciudadana que reconoce los derechos del "otro" independientemente de su condición socioeconómica.

Habrían también trabas culturales más allá del clasismo: el miedo al "contagio" de malas costumbres en los hijos producto del contacto interclases y la diferencia de los hábitos o formas de ocupar el espacio, son temores recogidos cualitativamente por nuestra investigación. Creemos que ellos podrían controlarse bajo formas específicas de diseño habitacional y urbano como, por ejemplo, los "microbarrios".

A nuestro juicio, es en la estructura social donde anidan los principales obstáculos para la integración residencial. Algunos de los problemas en este ámbito serían los altos precios del suelo - que hacen prácticamente imposible a la vivienda social competir con otros usos del suelo mejores pagadores-, una política habitacional segregadora y unos municipios que, por su escasa recaudación tributaria, carecen de los recursos necesarios para volverse lugares atractivos para grupos de mayores 
ingresos. No obstante, tales barreras estructurales muestran algunas tendencias que permiten pensar que es posible revertirlas, ya sea utilizando las fuerzas del mercado inmobiliario - aprovechando el hecho de que la cercanía a la vivienda social no reduce necesariamente el valor de otras propiedades, como muestra la experiencia internacional- o bien diseñando políticas que acorten la brecha entre la alta disposición a la integración y los impedimentos prácticos para alcanzarla.

Partiremos en la primera sección por definir qué se entiende por segregación residencial y, con base en la literatura y los estudios disponibles, discutir sus efectos negativos y la posibilidad de reducirla. Luego ofrecemos una reflexión crítica sobre las relaciones usualmente postuladas en el medio latinoamericano entre segregación, desigualdades y clasismo. En la tercera sección entregamos resultados de nuestros estudios empíricos que respaldan la conjetura de que en las ciudades chilenas existen espacios de libertad para alcanzar mayores grados de integración residencial que los que se observa. En la cuarta sección destacamos algunos desafíos de política pública que surgen de estos hallazgos.

\section{Segregación residencial: definición, efectos y mecanismos para su reducción}

Según Massey y Denton (1988), la segregación residencial es el grado en que dos o más grupos viven separados entre sí en distintas partes del entorno urbano. Identifican cinco dimensiones del fenómeno: uniformidad, exposición, concentración, centralización y agrupamiento. ${ }^{1}$ Así, un grupo social segregado sería aquel que no está uniformemente distribuido en el espacio urbano, que está mínimamente expuesto al contacto físico con miembros de otros grupos, que está espacialmente concentrado (en términos de una alta densidad geográfica), que está fuertemente centralizado (en el sentido de vivir cerca del área central de la ciudad) y que presenta un marcado agrupamiento territorial (Sabatini \& Cáceres, 2004).

En nuestro contexto hemos definido la segregación residencial como "el grado de proximidad espacial o de aglomeración territorial de las familias pertenecientes a un mismo grupo social, sea que este se defina en términos étnicos, etarios, de preferencias religiosas o socioeconómicos, entre otras posibilidades" (Sabatini, Cáceres \& Cerda, 2001). Asimismo, y luego de evaluar críticamente el índice de Massey y Denton, optamos por reducir las dimensiones de la segregación a tres: concentración (concentración de un grupo en el espacio), homogeneidad (homogeneidad social de un área) y prestigio social (dimensión subjetiva que alude al valor o estigma asociado a residir en un determinado lugar $\left.{ }^{2}\right)$.

Dependiendo de la dimensión, el grupo social y la escala que se considere, la segregación residencial puede volverse problemática; dicho de otro modo, la con-

1 En Massey y Denton (1988), evenness, exposure, concentration, centralization y clustering.

2 Respecto de la estigmatización, resulta interesante un estudio de Sampson y Raudenbush (2004), donde demuestran que las percepciones sobre el desorden social no solo se relacionan con las condiciones objetivas del entorno (desorden efectivo), sino también con el contexto racial y económico: As the concentration of minority groups and poverty increases, residents of all races perceive heightened disorder even after we account for an extensive array of personal characteristics and independently observed neighborhood conditions. 
centración de un grupo en un espacio no es negativa por sí sola. Por ejemplo, en el caso de la ciudad de Santiago, los hogares de mayores ingresos se concentran en el denominado "cono de alta renta", pero eso no significa que en esa zona solo habiten personas de clase alta. De hecho, es justamente lo contrario: el "cono" es la zona que ofrece mayor diversidad social de toda la ciudad, en el sentido de que es posible encontrar personas de todo el espectro social. Lo mismo ocurre en los conos de alta renta de las distintas ciudades latinoamericanas, que concentran los hogares de altos ingresos sin llegar a constituirse como espacios socialmente homogéneos. En este sentido, siguiendo la distinción de Clark ${ }^{3}$ entre etnocentrismo y hostilidad, las preferencias de segregación de los grupos afluentes latinoamericanos estarían más orientadas a agruparse con los similares (concentrarse) que a excluir a los diferentes (homogeneidad social), al contrario de la realidad estadounidense, donde campearía la "adolescencia urbana".

El problema ocurre cuando los espacios se vuelven homogéneos en pobreza a gran escala, como en el caso de la comuna de La Pintana. Aquí, la reunión en una amplia zona geográfica de una alta proporción de hogares pertenecientes a los dos quintiles más bajos (76 por ciento de estratos D y E el año 2002, fecha del último censo), les hace muy difícil entrar en contacto con familias de mayor nivel socioeconómico, que pudieran abrirles oportunidades laborales, información o amistad, entre otras posibilidades.

Este aislamiento se vuelve relevante en la medida en que el espacio no es tan solo el lugar donde ocurren determinadas acciones individuales o colectivas, sino también un lugar que produce realidades específicas. Mientras algunos autores se han abocado a identificar y medir los efectos negativos asociados a la segregación residencial de grupos desaventajados, otros han puesto el énfasis en la dirección complementaria, esto es, las consecuencias positivas asociadas al hecho de residir en áreas mixtas. En el contexto europeo y norteamericano casi siempre estas investigaciones consideran no solo la variable socioeconómica, sino también la étnica.

Entre quienes se han concentrado en el estudio de las consecuencias negativas que acarrea para las familias el hecho de vivir en áreas homogéneamente pobres, Flores (2006) identifica al menos tres corrientes o grupos de estudios, según cuál sea el eje en torno al que se articulan: geografía de oportunidad, efecto barrio o género. La geografía de oportunidad está definida por las posibilidades otorgadas por el Estado, el mercado y la sociedad de incorporarse a la previsión social, el trabajo y la educación. En las ciudades, la segregación de los grupos más pobres en zonas socialmente homogéneas no solo reduce las oportunidades a nivel de sus barrios, sino que origina mayores dificultades para visualizar y movilizar los activos existentes en

... preferences themselves are driven by positive feelings about one's own group, not negative feelings about out-groups (Clark, 1986, de acuerdo con la síntesis de Bobo y Zabrinsky, 1996).

4 Siguiendo la argumentación de Sennett (1970), hemos denominado "adolescencia urbana" al temor a ser confundido con el 'otro' de menor condición social pero parecido a mí (Sabatini \& Brain, 2008). Los grupos ascendentes, celosos de afirmar su nueva identidad de clase, rechazan abiertamente al grupo del cual provienen y al que, por lo mismo, se asemejan. Tal actitud "exclusionaria" puede presentarse a lo largo de toda la escala social, especialmente cuando la economía crece y la movilidad social ascendente se fortalece. 
la ciudad (Galster \& Killen, 1995; Wormald, 2007). El efecto barrio, consistente en el traspaso hacia los individuos de las características comunes del barrio (Flores, 2006), se materializaría principalmente mediante las redes sociales locales, tales como el efecto pares (Jencks \& Mayer, 1990), la socialización colectiva (Wilson, 1987) y la socialización institucional (Bauder, 2001). La tercera línea, representada por los estudios de género, sostiene que el acceso a las oportunidades se refleja de forma diferente en el espacio para hombres y mujeres, especialmente en el ámbito laboral (Flores, 2006).

¿Qué evidencia respecto de las consecuencias de la segregación hay para el caso chileno? Larrañaga y Sanhueza (2008), basándose en un panel de datos de corte transversal, encontraron que la segregación residencial afecta las oportunidades de niños y adolescentes más pobres, específicamente en lo que refiere a la asistencia a educación preescolar, el retraso escolar, la deserción escolar, y finalmente la inactividad juvenil. Sierralta (2010) obtiene similares resultados en jóvenes santiaguinos de extracción popular de entre 15 y 24 años en materia de inactividad juvenil, con diferencias en función del género. Adicionalmente, evidencia reciente muestra que hogares populares que habitan en viviendas sociales segregadas a gran escala enfrentan menos movilidad social y menores oportunidades si se los compara con hogares de la misma extracción social residentes en viviendas sociales localizadas en sectores con baja segregación (Sabatini, Wormald \& Salcedo, 2008).

Los estudios con foco en los efectos de residir en áreas mixtas consisten principalmente en evaluaciones de programas estatales que, con el fin de evitar la aglomeración de hogares vulnerables, promueven el desarrollo de viviendas económicas o sociales en áreas de ingresos medios y altos. Están las acciones que buscan conseguir más integración en los futuros desarrollos, y las que intentan corregir la ciudad existente y actúan sobre el parque habitacional. La experiencia internacional es rica en ejemplos de políticas que se enmarcan en obligaciones por parte del Estado o bien en incentivos para lograr el objetivo señalado, ya sea en los nuevos desarrollos o en el stock existente. En América destaca el caso de Estados Unidos, mientras que en Europa los principales precursores son el Reino Unido, Francia, Alemania, Suecia y Finlandia (Musterd, 2005).

En el marco de los incentivos, un caso destacable es el del estado de Massachusetts, Estados Unidos, cuya Constitución, en su capítulo 40B, establece incentivos para que las inmobiliarias construyan viviendas con densidad media por encima de la norma local en aquellos condados donde menos del 10 por ciento de las viviendas son "económicas" (Pollakoswki, Ritchay \& Weinrobe, 2005). En el caso de las obligaciones, conocido es el caso francés, que establece cuotas de 20 por ciento de vivienda económica en el parque habitacional de cada municipio urbano, y multas anuales por cada vivienda que falta para completar ese porcentaje. Este objetivo está resguardado desde el año 2000 por la Ley de Solidaridad y Renovación Urbana.

Entre los programas que han buscado caminos más complejos de fomento de la integración, está el plan HOPE VI en Estados Unidos, vigente desde 1992. Su finalidad ha sido diversificar los complejos de public housing por la vía de atraer a ellos 
a residentes de mayor condición social y, a la vez, dispersar a parte de sus residentes antiguos en pequeños conjuntos residenciales en los suburbios de clase media (Zhang \& Wiesmann, 2006). El objetivo de integración social ha sido entendido como el de crear "comunidades sustentables" (Popkin, 2006).

En Chile, a partir del año 2006, la política de vivienda ha considerado entre sus objetivos la promoción de una mayor "integración social” en las ciudades. Salvo por el "subsidio a la integración social", 5 las demás formas de integración impulsadas, como el Subsidio de Localización o el Programa Quiero Mi Barrio, no se basan específicamente en la reducción de la segregación residencial. Más bien, han buscado mejorar el acceso de los hogares a servicios o rehabilitar viejos barrios populares, respectivamente. En general, la reducción de la segregación es un área de la política pública en formación. ${ }^{6}$ Una iniciativa más radical del año 2006, la de crear una norma que impusiera una cuota de 5 por ciento del suelo de los nuevos desarrollos para vivienda social, despertó una fuerte resistencia y no alcanzó a llegar al Parlamento.

A escala internacional, la promoción de desarrollos urbanos mixtos ha suscitado discusiones sobre los costos económicos, sociales y urbanos — en los barrios mismos - que la mixtura pudiera generar.

En cuanto a los costos económicos, el principal temor es que las propiedades de mayor valor vean afectada su plusvalía, ya sea porque disminuya su valor o se incremente menos que el de unidades no mezcladas. $\mathrm{Al}$ respecto, diversos estudios realizados en Estados Unidos (Cummings \& Landis, 1993; Siegel, 1998; Maxfield Research, 2000; National Association of Home Builders, 1999; Green, Malpezzi \& Seah, 2002; Wilkins, 2002; Pollakowski et al., 2005; Gornstein \& Verrilli, 2006) han mostrado que los conjuntos mixtos no afectan significativamente el valor de las unidades de mayor valor que los integran ni tampoco el de las propiedades vecinas; es más, pueden generar efectos positivos cuando contribuyen a la rehabilitación o mejoramiento de zonas deterioradas (Goetz, Lam \& Heitlinger, 1996).?

En el plano de los efectos sociales y urbanos, ha habido medición de los impactos de mediano y largo plazo de programas residenciales integrados. Varios estudios han encontrado efectos positivos asociados a los mismos. Un hallazgo relevante descansa en el hecho de que la integración de los residentes de menores ingresos a los barrios de clase media continuaba en el tiempo en los barrios de clase media, sin que fueran re-segregados. Si bien el proceso de su aceptación fue lento, no se registraron conflictos significativos (Rosembaum, 1995). ${ }^{8}$ Un caso más reciente fue el que afectó al municipio de Yonkers en el área metropolitana de Nueva York. Como parte del HOPE VI, en 1990 la Corte Federal de Estados Unidos impuso al

5 "Bono de integración social" creado bajo la administración Bachelet (2006-2010), de unos 4.000 dólares, que se suma al subsidio habitacional para grupos medios (DS40), pudiendo llegar a duplicarlo. Se otorga a hogares que compran su vivienda en conjuntos que incluyen al menos un 30 por ciento de viviendas para hogares más pobres (Subsidio FS1 o FS2).

6 El Subsidio a la Integración Social, el único que claramente busca fomentar la mezcla social residencial, ha tenido poca aplicación y sus efectos están en estudio por un equipo de ProUrbana, Políticas Públicas, PUC.

7 Para ver un resumen de los resultados de estos estudios, consultar Myerson (2003) y ProUrbana (2007). Estas referencias fueron extraídas de dichos artículos.

$8 \quad$ Orfield (1997) resume los hallazgos de esos estudios. 
municipio un programa de de-segregación de la vivienda pública, consistente en la construcción de doscientos townhouses en siete sitios repartidos por barrios de clase media y alta para alojar a residentes de los antiguos complejos de public housing. A pesar de la gran conflictividad que rodeó este programa, las hipótesis de la debacle inmobiliaria y de los conflictos y efectos sociales negativos han sido descartados por distintos estudios (entre ellos, el de Briggs, Darden \& Aidala, 1999).

\section{Desigualdades, clasismo y segregación}

En esta sección argumentaremos que, sin importar cuál sea nuestra perspectiva teórica sobre los patrones culturales, el clasismo y la reducción de la segregación residencial son hechos enteramente compatibles en ciudades como las latinoamericanas.

Resulta de sentido común para muchas personas, probablemente la mayoría, afirmar que en Chile no es posible mezclar o acercar en el espacio a los grupos sociales. El clasismo nos impediría construir próximas las residencias de hogares de diferente condición social. . Chile es la sociedad "más clasista en América Latina", dice la escritora Elizabeth Subercaseaux, sin aportar pruebas pero interpretando a muchos chilenos. ${ }^{10}$ Lo mismo parecía tener en mente Felipe Morandé, decano de Economía de la Universidad de Chile, cuando hacía reparos a la intención del gobierno de la época de dictar una norma estableciendo cuotas de vivienda social en todos los desarrollos habitacionales. Medidas como esa han sido adoptadas en no pocos países para combatir la segregación residencial. Morandé objetaba el intento de crear "una convivencia social forzada", argumentando que las personas prefieren vivir con los de su misma clase y "no como vaca en corral ajeno" (El Mercurio, octubre 24, 2006).

Un punto de vista similar es el de los promotores inmobiliarios que rechazan asumir alguna responsabilidad en materia de control de la segregación residencial. Según Vicente Domínguez, presidente de la Asociación de Desarrolladores Inmobiliarios de Chile, la segregación sería atribuible al clasismo de los chilenos, hecho que los empresarios no pueden sino acatar de acuerdo con el principio de soberanía del consumidor. ${ }^{11}$ Desde la academia, Armando Roa (1997, p. 44) fundamenta la realidad clasista de los chilenos, aunque sin recurrir a ese adjetivo. Destaca "la dificultad de los chilenos para identificar a alguien como persona y valorarlo si no se averigua antes qué profesión tiene, cuáles son sus ideas políticas, sus gustos personales, la marca de su automóvil y hasta su vida íntima” —en definitiva, si no se sabe, en primer lugar, de qué clase de persona se trata.

9 Entenderemos por "clasismo" las valoraciones, actitudes y prácticas basadas en hacer diferencia, prejuiciar o discriminar a las personas según su condición social. Según el diccionario de la Real Academia Española, el clasismo es la actitud de quienes defienden la discriminación por motivos de pertenencia a otra clase social.

10 En convocatoria al seminario "Una mirada crítica al clasismo en Chile", realizado el 20 de mayo de 2010 en el Auditorio de la Facultad de Ciencias Sociales e Historia de la Universidad Diego Portales.

11 Opinión vertida en el seminario internacional "Integración social urbana y negocio inmobiliario: ęuna sociedad posible?, organizado en Santiago por ProUrbana-PUC y el Lincoln Institute of Land Policy, septiembre 11 y 12 de 2008. 
Parece innegable que las desigualdades sociales son un elemento sobresaliente en la estructura social chilena; y el reparo que aquellas suscitan, un hecho cultural clave. Así se puede comprender la sensación omnipresente e incómoda de clasismo que experimentamos los chilenos. Pero las desigualdades y las diferencias de riqueza y de poder no excluyen el orden social ni la cohesión. En tanto existan expectativas de movilidad social, dice Saraví, la persistencia de las desigualdades sociales no significa necesariamente pérdida de cohesión social. ${ }^{12}$ De hecho, esas expectativas han sido importantes en el Chile de los últimos decenios en la medida en que ha habido crecimiento económico y reducción de pobreza. Sin embargo, aun en la ausencia de tales expectativas, desigualdad y cohesión no son necesariamente antitéticas.

La cultura está construida en algunas tensiones claves, siendo quizá la más evidente para los latinoamericanos la que emana de la desigualdad de poder y de fortuna entre las personas. Otras son las que enfrentan lo nuevo con lo viejo, el contenido con la forma, la libertad con el orden establecido. La vida, dice Simmel (2000), se expresa y realiza por ciertas formas culturales (arte, religión, ciencia, tecnología, leyes) que, una vez creadas, toman identidades fijas y una cierta rigidez; "la vida se enfrenta permanentemente a sus propios productos, los cuales han cristalizado y no pueden moverse con ella” (p. 318).

Bauman (2010) amplía esta perspectiva con su "paradoja de la cultura”: esta presenta una "ambivalencia nuclear" entre sus dos caras, la de creatividad y la de regulación normativa; entre el azar y el orden social; entre la libertad y creatividad desplegadas para construir un orden social, y los necesarios límites a la libertad para defender ese orden, una vez construido. La libertad de unos para alcanzar sus objetivos contrasta con la pérdida de libertad de los que podrían resistirse a los primeros; en último término, "la libertad es una relación social" (Bauman, 2010, p. 18).

Las ciencias sociales intentaron por más de un siglo resolver esta paradoja reduciendo la cultura a una de sus dos caras, la del orden construido, enfoque que alcanzara su máxima expresión con el sistema teórico elaborado por Talcott Parsons (Bauman, 2010, p. 28). Para el "funcionalismo estructural", la cultura es un sistema compartido de valores, creencias y normas que estructura el sistema social (Parsons, 1968). Un énfasis excesivo en el orden establecido llevaba a los funcionalistas a desvalorizar el polo creativo y libertario de la cultura e, incluso, a tratarlo como "desviación” que debía ser corregida por la capacidad autorregulatoria del sistema social.

Si asumimos la perspectiva del funcionalismo, la cultura chilena sería la de las clases altas: aquella "de corte paternalista" y "alejada de la igualdad" que exhibe una “impronta premoderna," según Bengoa (1996, p. 57). Aun si la cultura chilena fuera explicada en su totalidad por este "centralismo paternalista" (Véliz, 1970) y, por lo mismo, el clasismo fuera rampante, ubicuo e incontestado, los integrantes de las diferentes clases sociales podrían asentarse en las ciudades sin mostrar mayor

Opinión vertida en el taller internacional del proyecto "Cultura de integración y cohesión social en las ciudades chilenas" (2009-2011) (Proyecto Anillos 2 - II Concurso de Anillos de Investigación en Ciencias Sociales), realizado en Santiago de Chile los días 17 y 18 de mayo de 2010, institutos de Sociología y de Estudios Urbanos (PUC)/Programa Bicentenario en Ciencia y Tecnología (Conicyt). 
segregación residencial. Hay antecedentes de esta combinación entre desigualdades y mezcla social en el espacio. En los albores de la industrialización capitalista, cuando la sociedad inglesa aún conservaba mucho de un sistema de castas, "la distancia social era tan marcada que los privilegiados no sentían necesidad de protegerse aún más de los pobres por medio de la distancia física," según Fishman (1987, p. 32). ${ }^{13}$ Esta "combinación de proximidad física y vasta distancia social", para usar la expresión de Watt (1963; citado por Fishman, 1987, p. 32), se explica, para el caso de América Latina, por la informalidad e ilegalidad en el acceso al suelo de las clases populares, predominante en estas ciudades (Roberts \& Wilson, 2009a, p. 7), pero, asimismo, por un factor sociológico: la presencia física de la persona de condición social subalterna permite reafirmar la propia identidad como integrante de las clases superiores.

En la formación de los "barrios altos" de las ciudades chilenas, así como en la actual dispersión de condominios hacia la periferia popular, ha ocurrido una poco reconocida aproximación física entre grupos sociales. De hecho, la suburbanización de las elites que originó, entre fines del siglo XIX y comienzos del XX, los "barrios altos" de las dos principales ciudades chilenas, Valparaíso y Santiago, tomó forma en áreas que se encontraban considerablemente pobladas por clases populares (Cáceres \& Sabatini, 2007).

En todo caso, el centralismo paternalista es solo una parte del espectro cultural de la sociedad chilena y, específicamente, de la forma en que se relacionan las clases sociales. La aceptación de las desigualdades y las jerarquías sociales no ha estado ni cerca de haber sido completa. No se podría, sin riesgo de falsear los hechos, reducir las expresiones de rechazo a las desigualdades y el clasismo a meras "desviaciones". Lo mismo podría decirse de las formas culturales locales que se apartan de la cultura oficial. El estructural-funcionalismo no parece un enfoque que permita captar los sentimientos y significados que bullen en las clases medias y populares, por lo que se hace necesario recurrir a enfoques que entiendan la cultura como internamente tensionada.

Para Gramsci (1985), la cultura está formada por capas de significados decantados históricamente y no necesariamente coherentes entre sí; dichas capas serían estratos culturales que se originan en ideas dominantes de épocas pretéritas, que se han sedimentado en el sentido común de los grupos que conforman la masa o población de una sociedad en un momento dado. Esta noción parece especialmente adecuada para sociedades - como las latinoamericanas - con amplias capas populares que nunca se constituyeron plenamente en proletarias (Portes \& Hoffman, 2003) y cuya clase capitalista no se liberó de la tradición ni de los intereses latifundiarios (Zeitlin \& Ratcliff, 1988).

Se podría sostener que toda sociedad contemporánea arma su patrón cultural con la combinación de la vieja sociedad agraria, la oferta democrática de la modernidad, y la amenaza latente y episódica del desorden; y lo propio de Chile en ese 
sentido - y en buena medida de América Latina - sería que en esa combinación ha sido débil el segundo componente. Sin embargo, parece innegable que en el último tiempo "los procesos democráticos han conocido una significativa revaloración y expansión” (Zamorano, 2008, p. 261).

En el marco del liberalismo y de la reducción de la pobreza asociada al crecimiento económico y la ampliación de las clases medias, ha habido avances en materia de derechos ciudadanos, aunque tal vez más en términos de legitimidad que como derechos observados. Y esos derechos ciudadanos incluyen los de progresar materialmente y acceder a una vivienda, ojalá bien localizada, cerca de los servicios y las oportunidades y en barrios que ayuden a los proyectos familiares de movilidad social. ${ }^{14}$

Como amalgama de capas sedimentadas, nuestra cultura alojaría tensiones entre la propuesta cultural de las elites, más coherente, y los significados atesorados por las masas, acrisolados en el "sentido común" (Gramsci, 1985). Ortiz (1980) destaca el importante papel del "sentido común" como forma de sincretismo, como búsqueda nunca lograda de coherencia entre las capas de significados en que consiste la cultura popular. Para Bauman (2001), en tanto, la ambivalencia no solo sería consustancial a la cultura sino "el producto principal de la actividad de la cultura", de tal manera que "la cultura respalda la causa de la libertad" (pp. 160-161). Es más, la combinación entre libertad y orden que define a la cultura se inclinaría hoy, bajo la "modernidad líquida", en favor de "nuevas experimentaciones y cambios" (Bauman, 2010, p. 33).

En suma, desde nuestro interés en las desigualdades sociales, el encuentro con el "otro" de diferente condición social es la relación nuclear que sostiene el orden social. Esa relación de contraste cobija tanto las formas verticalistas de cohesión social que combinan paternalismo y sometimiento, como las formas más horizontales, en expansión hoy, fundadas en el reconocimiento de los derechos de las personas. Lo propio de América Latina serían los patrones internamente tensionados entre clasismo e integración, en que las desigualdades pueden ser la forma específica de cohesión (en el patrón cultural dominante del "centralismo paternalista") y, al mismo tiempo, resistidas para ser reemplazarlas por formas horizontales de integración y cohesión (en el patrón cultural del ciudadano).

Podrían, entonces, existir posibilidades culturales de integración residencial en la línea de la cultura ciudadana, porque la cultura es de capas; pero, también, obstáculos culturales (todo tipo de prejuicios y temores clasistas), obstáculos materiales (el precio de las viviendas, las políticas de vivienda social que favorecen la segregación espacial), lo mismo que posibilidades estructurales o materiales, como las de una gentrificación que no da lugar al desplazamiento de residentes en zonas populares. ${ }^{15}$

Entonces, sea cual sea el peso de esas capas de significados, no parece haber impedimento cultural para que se reduzca la segregación espacial entre las clases so-

14 La alta prioridad que otorgan los residentes de ciudades chilenas a la localización de sus viviendas fue un hallazgo del estudio de ProUrbana y el Observatorio Social de la Universidad Alberto Hurtado (OSUAH) (2006) sobre preferencias de regulación urbana, basado en una encuesta representativa aplicada a residentes de Santiago, Valparaíso y Concepción.

15 Sobre la posibilidad de una "gentrificación sin expulsión", véase Sabatini, Váquez, Robles y Rasse (2010). 
ciales en las ciudades chilenas. Esto permitiría comprender, además, la disminución de la segregación en algunas ciudades de América Latina (Sabatini, 1997; Roberts \& Wilson, 2009b, p. 221; Dureau \& Salas, 2010).

Aun así, la "tesis del espejo" (que las desigualdades sociales se reflejan en segregación espacial) y aquella sobre la "ciudad dual” (Mollenkopf \& Castells, 1991) siguen siendo populares, tal vez porque es la manera más simple de relacionar "lo social" con "lo espacial", siendo esta una vinculación que siempre ha complicado a las ciencias sociales. Las desigualdades sociales se reflejarían en el espacio lo mismo que la reestructuración del capitalismo impactaría al territorio. Desde los enfoques estructuralistas sobre la globalización se llama la atención sobre los impactos espaciales o territoriales de la globalización, implícitamente asumiendo que la realidad social y las fuerzas y proceso que la componen tienen existencia fuera de la realidad espacial sobre la que "impactan”. Sin embargo, nos advierte Harvey (2011), "el desarrollo geográfico desigual no es una cuestión incidental en el funcionamiento del capitalismo, sino que esencial en su reproducción” (p. 213). ${ }^{16}$ Como geografía compleja y cambiante, la segregación residencial es un factor de creciente importancia, entre otros, en el negocio inmobiliario y en la formación y defensa de las identidades sociales en la ciudad.

Debemos, entonces, poner en duda la convicción sobre la virtual imposibilidad de disminuir la segregación residencial. Hay importantes tendencias, espontáneas o inducidas por los mercados inmobiliarios, de aproximación física entre los grupos sociales, más allá de que persistan, por cierto, tendencias de incremento de la segregación. Están la dispersión espacial de viviendas para grupos medios y altos, aun en la periferia de bajos ingresos, así como la "inclinación estructural" de los hogares vulnerables por penetrar la ciudad en contextos de precariedad laboral e inseguridad económica (Sabatini \& Cáceres, 2004).

\section{Resultados empíricos}

La idea de que existe espacio para ampliar los niveles de integración residencial en nuestras ciudades, a pesar de la existencia de altos índices de desigualdad y de la persistencia del clasismo como elemento cultural en nuestra sociedad, se basa no solo en la bibliografía y datos secundarios ya descritos, sino también en el análisis de resultados de dos estudios que se centraron específicamente en este tema. Estos estudios son: i) "Disposición a la integración social urbana en Santiago, Antofagasta y Temuco: Una mirada desde la integración residencial”, o “estudio DIS”, realizado en 2008 por ProUrbana-PUC y el Observatorio Social-UAH para el Ministerio de Vivienda y Urbanismo; y ii) "Cultura de integración y cohesión social en las ciudades chilenas", o "estudio Anillos”, del Programa Bicentenario en Ciencia y Tecnología de Conicyt, Concurso Anillos de Investigadores en Ciencias Sociales, iniciado el año 2009 y encabezado por los institutos de Sociología y de Estudios Urbanos-PUC.

16 Uneven geographical development is not a mere sidebar to how capitalism works, but fundamental to its reproduction. Traducción de los autores. 
La primera investigación aportó datos cuantitativos recogidos mediante 1.779 encuestas aplicadas en Santiago, Antofagasta y Temuco, y datos cualitativos de doce grupos focales conducidos en barrios correspondientes a distintas situaciones urbanas en estas tres ciudades.

CUADRO 1 | Cuadro resumen de datos aportados por estudio "Disposición a la integración social urbana en Santiago, Antofagasta y Temuco” (estudio DIS)

\begin{tabular}{|c|c|c|c|}
\hline \multicolumn{4}{|c|}{$\begin{array}{l}\text { ESTUDIO: "DISPOSICIÓN A LA INTEGRACIÓN SOCIAL URBANA EN SANTIAGO, ANTOFAGASTA Y TEMUCO: UNA } \\
\text { MIRADA DESDE LA INTEGRACIÓN RESIDENCIAL" }\end{array}$} \\
\hline \multicolumn{3}{|c|}{$\begin{array}{l}\text { ENCUESTA CON DATOS ESTADÍSTICAMENTE } \\
\text { REPRESENTATIVOS DE } 3 \text { CIUDADES: }\end{array}$} & $\begin{array}{c}\text { GRUPOS FOCALES EN I } 2 \text { CONJUNTOS EN DISTINTAS } \\
\text { SITUACIONES } \\
\text { URBANAS: }\end{array}$ \\
\hline Antofagasta & $\mathrm{N}^{\circ}$ de encuesta & $\begin{array}{l}\text { Error Muestral } \\
\qquad[1]\end{array}$ & $\begin{array}{l}\text { Casos de conjuntos de NSE alto: } \\
1 \text { en área de NSE alto homogéneo } \\
1 \text { en área de menor NSE } \\
1 \text { que ha recibido como vecino un conjunto de vivienda } \\
\text { social }\end{array}$ \\
\hline Gran Stgo. & 1049 & $5,10 \%$ & $\begin{array}{l}\qquad \text { Casos de conjuntos de NSE medio: } \\
1 \text { en área de NSE medio homogéneo / } 1 \text { NSE medio-alto } \\
\text { homogéneo } \\
1 \text { que ha recibido como vecino un conjunto de vivienda } \\
\text { social } \\
1 \text { que ha recibido como vecino un conjunto de mayor NSE }\end{array}$ \\
\hline \multicolumn{3}{|c|}{$\begin{array}{l}\text { [1] Para muestra aleatoria al interior de cada estrato, con } \\
\text { varianza máxima y nivel de confianza igual a } 95 \% \text {. }\end{array}$} & $\begin{array}{l}\text { Casos de conjuntos de NSE bajo: } \\
1 \text { en área de NSE bajo homogéneo } \\
1 \text { en área de mayor NSE } \\
1 \text { que ha recibido como vecino un conjunto de mayor NSE }\end{array}$ \\
\hline
\end{tabular}

El segundo estudio, aún en desarrollo, aporta al análisis diecinueve entrevistas en profundidad a jefes de hogar y dueñas de casa en barrios de Santiago con diferente nivel de segregación y cuyos hijos asisten a colegios con distintos niveles de heterogeneidad social.

Los resultados de dichos estudios permiten señalar que, así como el aumento de la desigualdad no necesariamente está acoplado a un aumento de la segregación, la existencia de clasismo -o bien la percepción común respecto de que somos un país clasista - no necesariamente tiene como consecuencia que la mezcla de clases sociales en los barrios sea imposible.

De esta forma, para entender cómo personas que viven en barrios y comunas homogéneas pueden, al mismo tiempo, sostener un discurso a favor de la integración residencial, es necesario distinguir en el fenómeno de la integración-segregación residencial los siguientes aspectos: i) sus elementos discursivos o valorativos; ii) las actitudes; y iii) las conductas. Considerar los diversos elementos en torno a la disposición de las personas a la integración residencial permite desarrollar una concepción menos totalizadora respecto del fenómeno, y abrir espacios para la política pública en el tema. 
CUADRO 2 | Distribución de las entrevistas según tipo de barrio y de colegio, estudio "Cultura de integración y cohesión social en las ciudades chilenas" (estudio Anillos)

\begin{tabular}{|c|c|c|c|}
\hline \multirow{2}{*}{$\begin{array}{c}\text { COMPOSICIÓN SOCIAL } \\
\text { DEL BARRIO }\end{array}$} & \multicolumn{3}{|c|}{ COMPOSICIÓN SOCIAL DEL COLEGIO O LICEO } \\
\hline & HOMOGÉNEO NSE ALTO & HETEROGÉNEO & HOMOGÉNEO NSE BAJO \\
\hline Homogéneo NSE alto & 2 hogares de NSE alto & 1 hogar NSE alto & \\
\hline Homogéneo NSE medio & 2 hogares de NSE medio & 3 hogares de NSE medio & \\
\hline Homogéneo NSE bajo & & 1 hogar NSE bajo & 1 hogar NSE bajo \\
\hline \multirow[t]{3}{*}{ Heterogéneo } & 2 hogares NSE alto & 1 hogar NSE alto & \\
\hline & 2 hogares NSE & 2 hogares NSE & 1 hogar NSE bajo \\
\hline & & 1 hogar NSE bajo & \\
\hline SUBTOTAL ENTREVISTAS & 8 & 9 & 2 \\
\hline
\end{tabular}

\section{Discurso}

Más allá de las decisiones sobre el lugar y tipo de residencia de cada persona, es llamativo que la mayor parte de nuestros entrevistados, independientemente de su edad, estrato socioeconómico o sexo, piense que es bueno que la gente más acomodada viva cerca de gente más pobre.

Por una parte, se atribuye a la proximidad una serie de beneficios funcionales para las personas de menores recursos, como mejor infraestructura y equipamiento urbano, así como oportunidades laborales y acceso a servicios en el vecindario. Por otra parte, hay quienes señalan que vivir cerca de los más pobres puede generar aprendizajes para quienes tienen más recursos, por ejemplo con relación a virtudes como la solidaridad y el esfuerzo.

GRÁfICO 1 | Porcentaje de encuestados según nivel de acuerdo frente a la frase "Creo que es bueno que personas de distinta clase social vivan cerca", por ciudad

\begin{tabular}{|c|c|c|c|c|}
\hline & $\begin{array}{l}\text { Muy de acuerdo o De acuerdo } \\
\text { Ni de acuerdo ni en desacuerdo } \\
\text { Muy en desacuerdo o En desacuerdo }\end{array}$ & & & \\
\hline SANTIAGO & 54,6 & 16,3 & 29,1 & \\
\hline TEMUCO & 73,5 & & 14,9 & 11,6 \\
\hline ANTOFAGASTA & 75,3 & & 12,8 & 10,9 \\
\hline
\end{tabular}

FUENTE ESTUDIO DIS, 2008.

NOTA No SE REgISTRAN DIFERENCIAS SIGNIFICATIVAS SEGÚN NIVEL SOCIOECONÓMICO (NSE), SEXO O EDAD. SOLO SE REGISTRAN LAS DIFERENCIAS POR CIUDAD EXPUESTAS EN EL GRÁFICO. 


\section{CUADRO 3 | Nivel de acuerdo con efectos funcionales positivos de integración residencial}

\begin{tabular}{|c|c|c|c|c|}
\hline & $\begin{array}{c}\text { MUY DE } \\
\text { ACUERDO } \\
\text { / DE ACUERDO }\end{array}$ & $\begin{array}{c}\text { NI DE } \\
\text { ACUERDO NI EN } \\
\text { DESACUERDO }\end{array}$ & $\begin{array}{c}\text { MUY EN } \\
\text { DESACUERDO/EN } \\
\text { DESACUERDO }\end{array}$ & TOTAL \\
\hline $\begin{array}{l}\text { Evita que las personas de menores recursos } \\
\text { sean discriminadas por el lugar en que } \\
\text { viven }\end{array}$ & 73 & 13,2 & 13,8 & 100 \\
\hline $\begin{array}{l}\text { Permite a las personas de menores recursos } \\
\text { acceder a mejores oportunidades de trabajo }\end{array}$ & 81,3 & 12,4 & 6,3 & 100 \\
\hline $\begin{array}{l}\text { Permite a las personas de menores } \\
\text { recursos acceder a mejores servicios, como } \\
\text { educación, salud, transporte, comercio } \\
\text { y plazas }\end{array}$ & 84,3 & 8,9 & 6,8 & 100 \\
\hline $\begin{array}{l}\text { Aumenta la confianza entre personas de } \\
\text { distintas clases sociales }\end{array}$ & 51 & 17,4 & 31,6 & 100 \\
\hline $\begin{array}{l}\text { Permite que las personas sean más } \\
\text { tolerantes a convivir con personas } \\
\text { diferentes }\end{array}$ & 59,6 & 19,8 & 20,4 & 100 \\
\hline $\begin{array}{l}\text { Permite que personas de distinta clase } \\
\text { social compartan espacios públicos }\end{array}$ & 74,6 & 15,4 & 10,1 & 100 \\
\hline Permite generar más vida de barrio & 65,6 & 23,5 & 10,9 & 100 \\
\hline $\begin{array}{l}\text { Permite que personas de distinta clase } \\
\text { social generen vínculos de amistad }\end{array}$ & 30,9 & 24,1 & 44,9 & 100 \\
\hline $\begin{array}{l}\text { Permite que personas de distinta clase } \\
\text { social conversen en las calles }\end{array}$ & 39,9 & 27,4 & 32,7 & 100 \\
\hline $\begin{array}{l}\text { Aumenta la delincuencia en los barrios de } \\
\text { clase alta }\end{array}$ & 67,6 & 13,4 & 19 & 100 \\
\hline $\begin{array}{l}\text { Puede disminuir el valor de las propiedades } \\
\text { de las personas de mayores recursos }\end{array}$ & 72,8 & 17,3 & 10 & 100 \\
\hline $\begin{array}{l}\text { Hace que los espacios públicos como } \\
\text { plazas, calles y veredas de los barrios de } \\
\text { mayores recursos se mantengan en peores } \\
\text { condiciones }\end{array}$ & 55 & 12,9 & 32,1 & 100 \\
\hline
\end{tabular}

FUENTE ESTUdIO DIS, 2008.

Mujer: - Yo creo que los niños aprenderían harto, verían hartas cosas, ahí se darían cuenta de cómo es la pobreza, de cómo vive el pobre o los papás o las mamás, o de cómo viven ellos, y yo creo que estarían agradecidos de la clase en donde viven ellos, aprenderían harto (estrato bajo).

INVESTIGADOR: - ¿Hay otras cosas buenas, positivas, que tú veas en esta diversidad? 
Mujer: - Que uno puede, de las experiencias de vida de personas distintas, puede tener amplitud; puede ver cosas que no había visto antes, puede escuchar relatos e historias, puede comprender cosas que uno no va a vivir, puede empatizar incluso con personas que nunca uno antes se había topado. Eso yo creo que es súper importante (estrato alto).

GRÁfICO 2 | Porcentaje de encuestados según nivel de acuerdo frente a la frase "La mayoría de la gente cree que es bueno que personas de distinta clase social vivan cerca", por ciudad

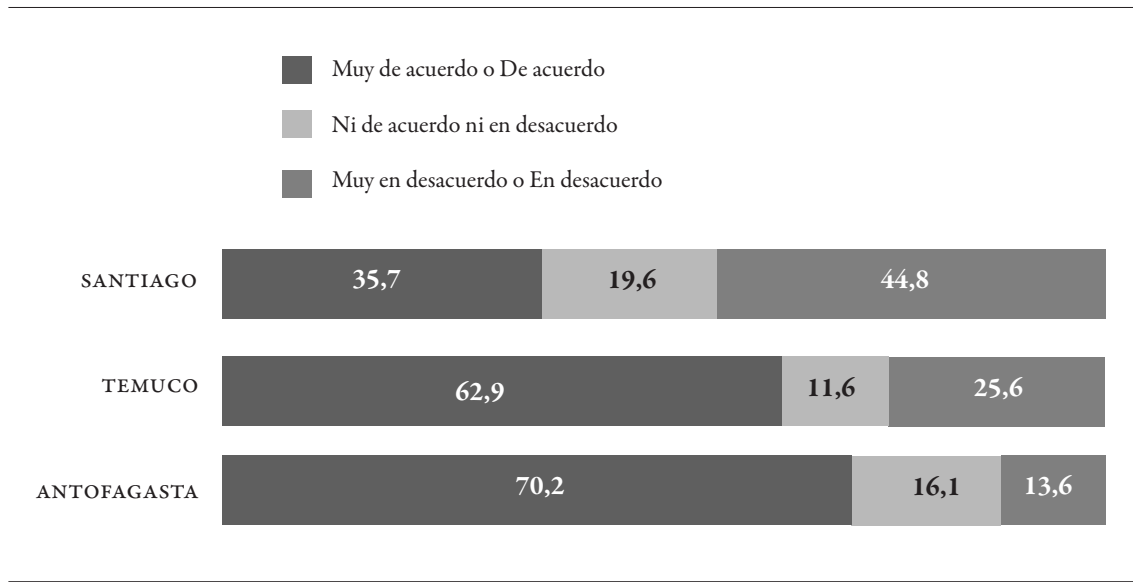

FUENTE EsTUdio DIS, 2008.

NOTA ADEMÁS DE LAS DIFERENCIAS POR CIUDAD EXPUESTAS EN EL GRÁFICO, TAMBIÉN SE REGISTRAN DIFERENCIAS POR NSE: EL NIVEL DE ACUERDO ES INVERSAMENTE PROPORCIONAL AL NSE, DE FORMA QUE MIENTRAS LOS ENTREVISTADOS DE ESTRATO ALTO PRESENTAN UN 11,8 POR CIENTO DE ENCUESTADOS MUY DE ACUERDO O DE ACUERDO, LOS DE ESTRATO BAJO PRESENTAN UN 58,4 POR CIENTO. NO SE REGISTRAN DIFERENCIAS SIGNIFICATIVAS POR SEXO O EDAD.

Estos altos niveles de acuerdo eran predecibles, en la medida en que se puede suponer que los entrevistados, por deseabilidad social, se declararían más entusiastas respecto de la integración de lo que realmente son. Por este motivo, se decidió preguntarles respecto de cuán integradoras son la mayoría de las personas, como una forma de acercamiento a lo que realmente piensan sobre la integración residencial.

Como era esperable, se obtuvo que los entrevistados, independientemente de su edad o sexo, se declaran como más integradores que el resto de la sociedad: a pesar de que la mayoría declara que es bueno que las personas de distinta clase social vivan cerca, cuando se les pregunta si la mayoría de la gente piensa así, los niveles de acuerdo bajan en todas las ciudades. Esto ocurre con especial fuerza en la clase alta, en que solo 11 por ciento de los encuestados declara que la mayoría de las personas cree que es bueno que la gente de distinta clase social viva cerca. Lo interesante es que, pese a que son más bajos que los declarados respecto de sí mismos, los niveles de acuerdo o indiferencia frente a la integración residencial son, en todas las ciudades, mayores al 50 por ciento. Esto revela la existencia de espacio para pensar en políticas pro integración, en la medida en que los niveles de desacuerdo frente a la integración residencial son más bien bajos. 
Es interesante, además, revisar lo que significa la existencia de deseabilidad social en esta respuesta: revela que estar a favor de la integración social es algo socialmente valorado y que, por lo mismo, es apreciado como negativo el cerrarse a dicha posibilidad. Más allá de las restricciones que las personas enfrentan al momento de tomar la decisión respecto de la localización de su vivienda, existe una predisposición inicial positiva hacia la integración residencial en la medida en que se la considera "buena" o "socialmente valorada".

Ahora bien, ¿por qué esta predisposición favorable no se manifiesta en menores niveles de segregación residencial? De acuerdo con nuestra conjetura, intervendrían factores que van desviando lo que las personas hacen de su orientación inicial. En principio, podría pensarse que esos obstáculos son principalmente económicos, como sería el precio de la vivienda. Sin embargo, es posible también constatar la influencia de trabas simbólicas, registradas especialmente a nivel perceptivo o de discurso. De hecho, el obstáculo que se erige con mayor fuerza a nivel de discurso es el "clasismo". Al consultar a las personas sobre las causas de la segregación residencial, un poco más de la mitad ( 56 por ciento) señaló como causa principal de la segregación residencial el que la gente es clasista y no quiere compartir su barrio, poniendo en segundo plano los problemas de oferta de viviendas y valor del suelo. En este tema se encontraron diferencias significativas con relación a la ciudad de residencia, sexo y clase social del encuestado. La causa atribuida al clasismo predomina en las clases medias, entre las mujeres, y se observa principalmente en Santiago y Temuco.

GRÁFICO 3 | Porcentaje de encuestados según causa de segregación residencial, por ciudad, sexo y clase social

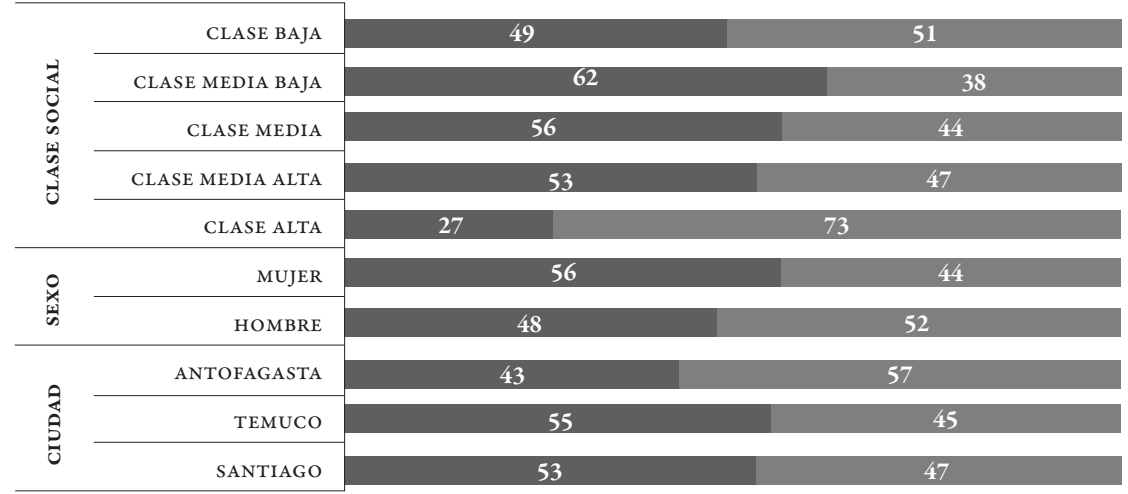

Los chilenos son clasistas y no les gusta compartir su barrio

Las casas en unos sectores son mucho más caras que en otros

FUENTE ESTUDIO DIS, 2008. 
INVESTIGADOR: - ¿Ustedes creen que eso [mezcla social] debería extrapolarse en realidad hacia otras comunas también de altos ingresos, en situación como de mezcla, o lo ven muy difícil? ¿Cómo imaginan eso?

Mujer: - Lo veo súper difícil, por el arribismo y el clasismo que hay en Chile. Es decir, como que te da mal currículum vivir cerca de gente de otra realidad social (estrato alto).

Entonces, es interesante la tensión que existe en el discurso de integración residencial de los habitantes de nuestras ciudades: por una parte, se la considera algo bueno y de valor y, al mismo tiempo, difícil de llevar a cabo, por la fuerza del clasismo en nuestra cultura. Sin embargo, nuestros entrevistados asignan al Estado un rol destacado en promover la integración de las distintas clases sociales en el espacio: la gran mayoría está de acuerdo con que el Estado debiera ser la instancia que busque disminuir la distancia geográfica entre las distintas clases sociales al interior de cada ciudad. A esto hay que sumar que una parte importante de los encuestados se manifiesta indiferente frente a la posibilidad de que el Estado intervenga, lo que amplía las posibilidades de intervención: lo importante no es que todos estén de acuerdo, basta con que sean indiferentes para que haya un espacio para intervenir.

GRÁFICO 4 | Nivel de acuerdo con la afirmación: "El Estado debe tratar que las distintas clases sociales vivan mezcladas al interior de la ciudad”, según clase social

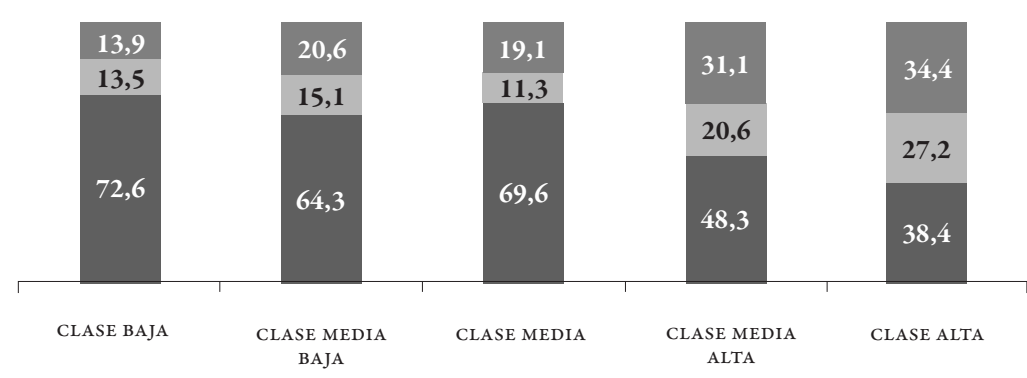

Muy de acuerdo o de acuerdo

Ni de acuerdo ni en desacuerdo

Muy en desacuerdo o en desacuerdo

FUENTE ESTUdio DIS, 2008.

NOTA TAMBIÉN SE PRESENTAN DIFERENCIAS SIGNIFICATIVAS POR CIUDAD: MIENTRAS UN 10 POR CIENTO DE LOS ENCUESTADOS DE TEMUCO ESTÁ EN DESACUERDO CON LA AFIRMACIÓN, EN ANTOFAgASTA LO ESTÁ UN 12 POR CIENTO, Y UN 26 POR CIENTO EN SANTIAgo. 
En la misma dirección que los datos anteriores, el 56 por ciento considera que deberían existir políticas de vivienda que permitan a los más pobres vivir en barrios de personas de mayores recursos.

Asimismo, en el estudio Anillos, el acuerdo con la intervención del Estado para generar mayor mezcla social estaba relacionado con mayores niveles de contacto y vínculos con personas de estrato bajo (controlando por nivel socioeconómico del encuestado). En este sentido, podemos pensar que tras los niveles de apoyo a la acción del Estado no hay solo deseabilidad social, sino también una actitud distinta y una base conductual diferente.

En suma, podemos constatar que, incluso remitiéndonos a lo que las personas declaran y valoran, hay evidentes tensiones y fragmentaciones en el ámbito del discurso. La integración se reconoce como un valor, y se identifican consecuencias positivas asociadas a ella, pero al mismo tiempo queda sujeta a las dificultades que le impone el arraigado clasismo de nuestra sociedad. En este sentido, lejos de cerrar la puerta a la integración residencial, esta tensión refleja inconsistencias en el discurso que pueden, finalmente, abrir oportunidades de integración.

GRÁFICO 5 | Nivel de acuerdo con la afirmación: "Deberían existir políticas de vivienda que permitan a los más pobres vivir en barrios de clase media o alta"

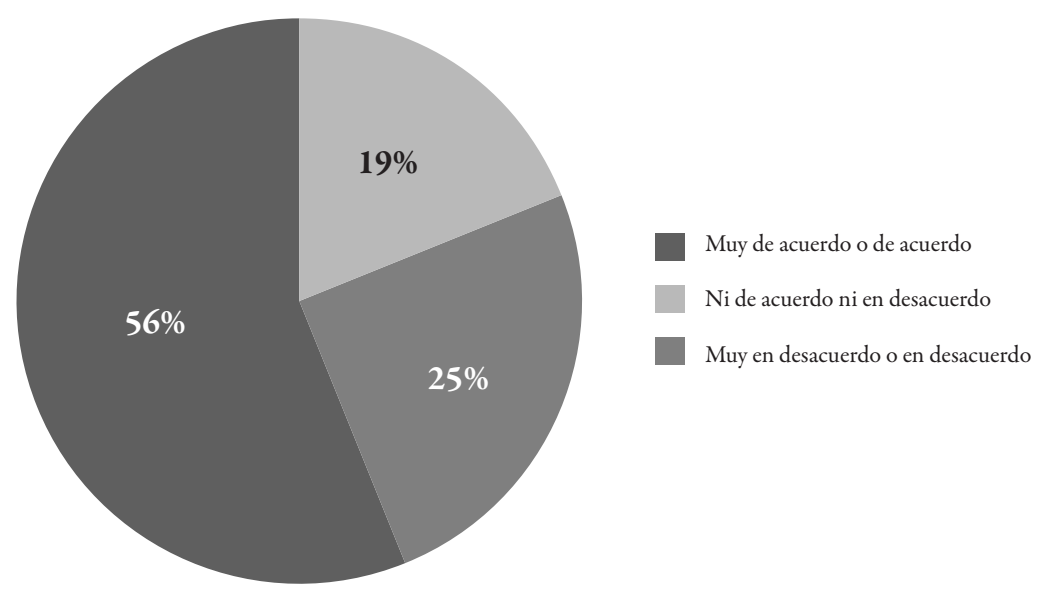

FUENTE ESTUdio DIS, 2008.

NOta Quienes presentan Mayor Desacuerdo son los encuestados de Santiago, y los de estrato bajo. NOTA QUIENES PRESENTAN MAYOR DESACUERDO SON LOS ENCUESTADOS DE SANTIAGO, Y LOS DE ESTRATO BAJO. TIENEN TEMOR A SER UBICADOS EN UN BARRIO DE MAYOR NIVEL SOCIAL. ESTO, SIN EMBARGO, ESTÁ VINCULADO A LA ESCALA: SI ESTÁN EN UN CONJUNTO DE ESTRATO BAJO EN UN SECTOR DE MAYOR NIVEL SOCIOECONÓMICO, EL TEMOR DESAPARECE. 


\section{Actitudes sobre la composición social del barrio}

Adicionalmente a las tensiones internas del discurso en torno a la integración residencial, existen elementos prácticos que dificultan a las personas mudarse a vivir en sectores mezclados socialmente. Así, a pesar de que la mayoría de los encuestados respondió que era bueno que las familias de diferentes clases sociales vivieran cerca, dos tercios de ellos (65 por ciento) preferirían vivir en un barrio con familias de su misma clase social y solo 17 por ciento declara que le gustaría que su barrio incorporara también familias de otras clases sociales. La actitud frente a la elección de la propia vivienda parece, al menos a primera vista, incoherente con el valor asignado a la integración residencial.

Es importante señalar que son los entrevistados provenientes de hogares de edad media (30-44 años) los que aparecen más reticentes frente a la integración residencial. ${ }^{17} \mathrm{El} 72$ por ciento de ellos manifestó preferencia por vivir en sectores residenciales con familias de su misma condición social, en comparación con 65 por ciento de los entrevistados de todas las edades. Si el rechazo a los más pobres en el barrio fuera un hecho cultural enteramente atribuible al clasismo, no cambiaría a lo largo del ciclo de vida, como de hecho lo hace. Los elementos culturales que configuran la actitud hacia los otros no cambian; lo que cambia son las circunstancias: hay etapas de la vida en que la convivencia con el otro aparece como más costosa.

\section{GRÁFICO 6 | Porcentaje de encuestados según preferencia de configuración social del lugar de residencia hipotético}

Que sea un sector de familias de una clase social menor a la suya

Que sea un sector de familias de una clase social mayor a la suya

Le son indiferentes las clases sociales que existan en el sector donde viva

Que sea un sector de familias de su misma clase social y de otras clases sociales

17 Así como los entrevistados de estratos medios y aquellos de Santiago, que también manifestaban una mayor proporción de preferencias hacia la homogeneidad social. 
En esta línea, es posible relacionar el cambio entre el valor asignado a la integración y la actitud individual más reacia, con una serie de costos que las familias deben enfrentar al vivir en barrios más mezclados socialmente. Las ventajas que se derivan de la integración residencial, como se revisó anteriormente, se localizan en el "otro" de menor condición social, o en la sociedad en su conjunto, mientras que los riesgos son específicos y recaen sobre los hogares de mayores recursos. Esto genera diversos temores asociados a la integración residencial en los hogares de mayores ingresos. Así, por una parte, las personas expresan temor de que disminuya el nivel social del área, lo que - creen ellos - contribuiría a un detrimento de las "plusvalías" (valor o valorización de las propiedades). Debido a la importancia de la vivienda como el principal elemento patrimonial de muchas familias, este miedo no es menor. De hecho, está en el centro del proyecto de movilidad social de cada hogar.

De repente he pasado seis meses ofreciendo una casa que normalmente la había arrendado en un mes. Y la ofrezco, la gente viene sin saber dónde queda, muchos me preguntan "ah, en ese barrio no". Pero cuando logran venir al cerro lo encuentran precioso, pero les molesta el entorno. Más que cualquier otra cosa (estrato alto).

Sin embargo, nuestros entrevistados nos sugieren que la diferencia de costumbres es lo que más preocupa. Puede generar roces y conflictos o, peor aún, "contagiar" a los propios hijos:

Debiera ser, pero la gente... del hecho que esa gente tiene otras costumbres, esa gente muy baja... hay que ver cómo es... cómo vive, cómo es su entorno, cómo cuidan a sus hijos, cómo andan sus hijos. Debiera ir como copiando, pero no es así (estrato medio).

En efecto, una de las mayores inquietudes que detectamos respecto de este tema es la crianza de los hijos. Esto explica, además, la menor disposición a la mezcla de los entrevistados en edad media, que probablemente corresponden a padres de familias en etapa de crianza. Antes que una sensación generalizada de inseguridad frente al delito - un temor que se podría anticipar, debido a la recurrente asociación que se hace en los medios y en el debate público entre pobreza y crimen-, lo que registra el estudio es un temor bien específico: que los hijos adquieran conductas que los padres desaprueban y que atribuyen a niños de inferior condición social. Tal temor podría abortar del todo la posibilidad del contacto social y los vínculos entre clases a nivel de los vecindarios. Sin embargo, al precisar la escala de la integración residencial se hace posible compatibilizar dicha reticencia con el valor que las personas de clases medias y altas otorgan a la integración residencial y los beneficios que le atribuyen.

En efecto, tanto la gente de estrato alto como aquellos de menores recursos prefieren tener vecinos de su misma clase social, pero nuestros datos sugieren que la escala en que lo desean es más bien pequeña. Se refieren al vecindario, a las cuadras 
que los rodean y en las que hacen su vida a pie, al lugar donde juegan sus hijos, al trayecto hacia el transporte o al parque donde pueden salir y tomar aire. Las personas de estratos medios y altos buscan de esa manera preservar los espacios públicos de conductas que les parecen inadecuadas y mantener la plusvalía del vecindario; por su parte, las de los estratos bajos buscan mantener su modo de vida y sus redes sociales. Pero, más allá de esta área cercana, no necesitan tanta homogeneidad. En su mayoría, nuestros entrevistados se presentan dispuestos a vivir en un sector diverso mientras su barrio más cercano sea homogéneo. En este sentido, hay algo de verdad en aquello de que "nadie quiere vivir como vaca en corral ajeno", pero esa verdad tiene un alcance no mayor a unas cuantas cuadras.

Por otra parte, si bien las personas prefieren vivir rodeadas de sus iguales en lo más próximo (su cuadra o su pasaje), dicha opción no es sinónimo de querer excluir a los diferentes. Hay una importante diferencia entre ambas actitudes. En ninguna de las opiniones recogidas los entrevistados manifiestan un ánimo "exclusionario" respecto de las personas de menor condición social. Sus reparos y cautela son específicos, incluyendo el aumento de la delincuencia, el deterioro de los espacios públicos y los problemas de convivencia en el barrio, fuera de los dos que hemos destacado antes - el menoscabo de las plusvalías y las malas influencias sobre los hijos-. Esto representa una importante ventaja en términos del diseño de políticas: si los reparos son específicos, son también subsanables. De hecho, solo 34 por ciento de los hogares de estratos medios y altos señala no estar dispuesto a recibir en su barrio a familias de menor clase social; el 25 por ciento está dispuesto sin condiciones, y 41 por ciento con algunas condiciones. ${ }^{18}$

GRÁFICO 7 | Porcentaje de encuestados de clase media y alta según disposición a recibir en el barrio a familias de clase social más baja, según clase social

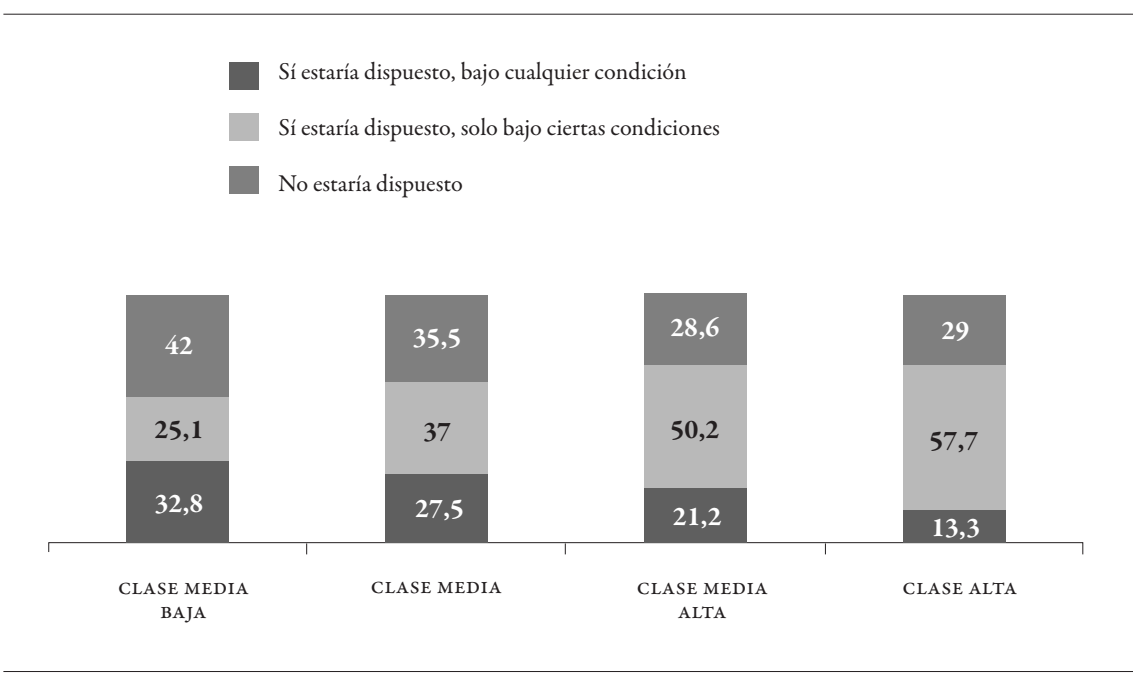

FUENTE Estudio DIS, 2008.

18 La disposición a la mezcla disminuye entre los mayores de 60 años, los hogares de estrato medio bajo, y aquellos del Gran Santiago. 
Estas condiciones tienen que ver tanto con elementos materiales (que no sean blocks de vivienda, que no sean muchas viviendas, que tengan bonita fachada, etcétera), como con elementos de convivencia (que no haya demasiado ruido, que el entorno del barrio se mantenga limpio, etcétera). De esta forma, si la mezcla se posibilita instalando algunas condiciones básicas, nuevamente es posible concluir que los elementos que dificultan la disposición a la mezcla no están en la cultura, sino en las circunstancias específicas en la que ella se da.

Asimismo, resulta conveniente poner estos reparos a la integración residencial en su justa dimensión. Si bien vimos que el 66 por ciento preferiría barrios compuestos por familias de su misma clase social, la composición social del barrio no es el factor más importante de los relativos a la localización preferida de una futura vivienda. Menos de un 18 por ciento de los de clase media o alta mencionan la composición social como el atributo más importante del barrio donde se mudarían. En este sentido, probablemente muchas personas estarían dispuestas a vivir con personas de otro estrato social si la localización ofreciera otros atributos que les parecen importantes (cercanía a los lugares que frecuentan, belleza del sector, etcétera).

\section{CUADRO 4 | Preferencias de localización según clase social}

\begin{tabular}{|c|c|c|c|c|c|c|}
\hline & $\begin{array}{l}\text { CLASE } \\
\text { BAJA }\end{array}$ & $\begin{array}{c}\text { CLASE } \\
\text { MEDIA } \\
\text { BAJA }\end{array}$ & $\begin{array}{l}\text { CLASE } \\
\text { MEDIA }\end{array}$ & $\begin{array}{c}\text { CLASE } \\
\text { MEDIA } \\
\text { ALTA }\end{array}$ & $\begin{array}{l}\text { CLASE } \\
\text { ALTA }\end{array}$ & TOTAL \\
\hline $\begin{array}{l}\text { Que quede cerca de los lugares que } \\
\text { su familia y usted frecuenta }\end{array}$ & 32,8 & 32,6 & 34,1 & 38,5 & 37,8 & 35,8 \\
\hline Que sea un lugar de alto nivel social & 4,6 & 8,5 & 8,1 & 4,7 & 6,6 & 6,8 \\
\hline $\begin{array}{l}\text { Que sea un sector donde la mayoría } \\
\text { de los vecinos sea de su misma clase } \\
\text { social }\end{array}$ & 21,8 & 17,5 & 16,5 & 10,1 & 11,4 & 14,1 \\
\hline $\begin{array}{l}\text { Que sea un sector donde vivan } \\
\text { personas de distintas clases sociales }\end{array}$ & 3,3 & 4,9 & 2,5 & 3,1 & 1,9 & 3,6 \\
\hline $\begin{array}{l}\text { Que quede cerca de autopistas y/o } \\
\text { buena accesibilidad a transporte }\end{array}$ & 9,9 & 10,3 & 11,2 & 27,6 & 24,6 & 16,8 \\
\hline $\begin{array}{l}\text { Que sea un sector bonito, con áreas } \\
\text { verdes y de recreación }\end{array}$ & 27,4 & 25,8 & 26,4 & 14,8 & 13,6 & 21,6 \\
\hline Otro & 0,3 & 0,4 & 1,2 & 1,3 & 4,2 & 1,3 \\
\hline TOTAL & 100 & 100 & 100 & 100 & 100 & 100 \\
\hline
\end{tabular}

FUENTE ESTUDIO DIS, 2008.

Un último aspecto que parece relevante de analizar en términos de actitud es la distinción que los diferentes grupos sociales, desde los estratos bajos hasta los altos, hacen entre pobres "meritorios" y "no meritorios".

Los entrevistados de todas las clases sociales trazan distinciones dentro del grupo de "los pobres", con base en criterios variados. Mientras los entrevistados de estratos medios y altos distinguen la "gente de esfuerzo" de los carenciados de 
origen desconocido, lo mismo que los "pobres de la comuna" de los “de afuera”, los residentes urbanos de extracción popular marcan fronteras entre los que provienen de "campamentos" (asentamientos irregulares) y los que no. Estas fronteras no son neutras, sino que representan distinciones valóricas, entre pobres "buenos" y "malos", o "meritorios" y "no meritorios".

Los sueldos son muy bajos, no subsisten si no...; entonces se necesitan unos a otros y eso les da una gran virtud, que es ese sentido de unidad natural. Eso creo que identifica a nuestra gente más humilde. Dentro de eso nunca falta el que es resentido y que "pucha", y que "pucha que la cuestión", y que está peleando, siempre mirando lo que no tiene en vez de salir. Pero es uno a lo mejor en un grupo, no son todos. El resto a la vez es alegre, o sea, son exuberantes en la alegría, tú los ves riéndose pero felices (mujer, estrato alto).

La clasificación entre buenos y malos pobres, entre merecedor y no merecedor de recibir ayuda social o auxilio estatal, ha sido recurrente en la historia (Tilly, 2000). Puede ser entendida como una forma de controlar y aprovecharse de ciertos grupos débiles percibidos como peligrosos o simplemente postulados como tales (Bauman, 2000, p. 104). Este peligro puede ser percibido, incluso, por categorías específicas de grupos populares frente a la ascendencia de otros grupos desde el fondo de la escala social.

Sin embargo, si bien es cierto que la construcción de esas categorías dicotómicas de pobres se acompaña de una inclinación por la exclusión, también muestra una disposición a la integración social de los "meritorios" o "buenos" pobres. Diferenciar entre buenos y malos pobres, un ejercicio analítico que en toda sociedad construye "ideológicamente" a las clases rechazables, lleva implícita al mismo tiempo una predisposición a integrar a los pobres y a fijar las condiciones para dicha integración. En último término, lo que se hace al distinguir entre pobres "meritorios" y "no meritorios" es diferenciar entre aquellos hogares de menores recursos con los cuales se puede generar algún tipo de identidad (por sus costumbres, por su estilo de vida, por ser de la misma comuna, etcétera) y aquellos con los que no existen planos de identidad posible.

Eso me preocupa. Mira si la cuestión... tienen la reja pintadita, el jardín bonito, es descueve (...) Pero pa' mí, amigable no es ver a un gallo estar sentado en la puerta de la casa con la botella de cerveza chupando; me molesta (mujer, estrato alto).

En el caso de las ciudades de Chile, parece obvio que el distingo entre buenos y malos pobres se relaciona con los afanes identitarios que podemos encontrar en distintos escalones de la estructura social y en diferentes lugares y momentos. Ni siquiera los grupos populares son ajenos a estas recurrencias sociológicas. Un importante hallazgo de nuestros estudios es, precisamente, la "adolescencia urbana" con la que personas de origen popular, medio o alto enfrentan la llegada de hogares de menor condición social a sus barrios, ya sea por el temor al cambio del estatus del barrio, o directamente por temor a ser confundidas.

La clasificación que hacen nuestros entrevistados de los habitantes más pobres entre buenos y malos es, además, parte de una serie de temores que usualmente mo- 
tejamos en su conjunto como clasismo. Sin pretender exhaustividad, destacamos los siguientes temores "clasistas" específicos:

a) El miedo al desorden social, hoy personificado en el "flaite" y antes genéricamente en el "lumpen-proletario". Este es, tal vez, el temor más ancestral de toda sociedad, temor que le confiere tanta importancia a la línea que dirime a los pobres entre buenos y malos.

No es porque te moleste tenerlo de vecino. No, el “ioye Luchoo!” no es el tema; es que lamentablemente es que... uno ve en las noticias, hay tiroteos, hay pandilleros... (mujer, estrato alto).

b) El temor a ser confundido con el "otro" de menor condición social, pero parecido a mí. Siguiendo la argumentación de Sennett (1970), hemos denominado este sentimiento como "adolescencia urbana". Los grupos ascendentes, celosos de afirmar su nueva identidad de clase, rechazan abiertamente al grupo del cual provienen y al que, por lo mismo, se asemejan. Tal actitud "exclusionaria" suele ser fuerte a lo largo de toda la escala social, especialmente cuando la economía crece y la movilidad social ascendente es más importante.

Es buen barrio, es buen barrio, pero estamos rodeado de ahí pa’ allá (...). De la que sigue esa calle pa' allá es como... no vai a ir a pasear pa' allá, no iría a andar en bicicleta pa' allá (...) no te vai a ir exponer a esas cosas que tú no lo haces. O sea, yo no me sentiría cómoda (mujer, estrato medio).

La gente que tiene más, hay gente que tiene y que nunca ha tenido, entonces después es como... miran así, como diciendo, con qué hombro, ni que fuera extraterrestre (...) se hacen más los importantes, después tienen su caída profunda (mujer, estrato bajo).

c) La tensión entre las dos capas más orgánicas de nuestros patrones culturales - la tradicional y la moderna-, que se expresa como temor de cada persona a la disolución de la propia identidad social en la horizontalidad de los valores democráticos, y que se vive como descalificaciones clasistas que se cuelan en las discusiones cruzadas entre lo heredado (ya sea esto linaje, herencia cultural o material) y meritocracia. En concreto, la crítica a los chilenos como "arribistas" que hicieron muchos de nuestros entrevistados revela una resistencia a un fenómeno universal de la cultura moderna, como es la movilidad social. Solo desde el apego a la sociedad estamental y jerárquica tradicional se puede entender este fastidio con los que, más neutramente, podemos reconocer como grupos socialmente emergentes.

Mujer: - Hay de todo. Yo te diría que eso es parte del arribismo; yo te decía, entonces, hay todo un afán de tener... y yo creo que para mí la clase socioeconómica alta es más alta y dice relación también no solo con medios, pero no solo con medios, sino también con todo el tema que yo te decía: el tema cultural, el acceso a la cultura, el poder estudiar afuera, o sea hay...

INVESTIGADOR: - Esa diferencia todavía existe. 
MUJER: - Si poh, claro, eso existe y entre ese y el arribista hay una gran diferencia, te fijas... El arribista a lo mejor se va a veranear afuera pero solo para decir que veraneó fuera de Chile, o sea no por cultura, no por querer que los chiquillos estudien y tengan su... ¿ ¿me entiendes? O sea, es otro el concepto y ese es el que me molesta, no el otro. El otro me da lo mismo (mujer, estrato alto).

\section{Conducta}

A pesar de los importantes factores que dificultan el que las familias puedan establecerse en barrios socialmente diversos, quienes pueden decidir su localización, esto es, las familias de estratos medios y altos, viven en sectores más heterogéneos que aquellas que no pueden decidir. En efecto, más allá de las pocas cuadras en que es mayoritaria la preferencia de todas las clases sociales por la homogeneidad entre vecinos, la diversidad social de las áreas residenciales es mayor entre los que más pueden elegir su barrio.

CUADRO 5 | Percepción de clase mayoritaria en la cuadra o pasaje, según clase social (residentes de Santiago, Antofagasta y Temuco) (porcentajes)

\begin{tabular}{|c|c|c|c|c|c|c|c|}
\hline & & \multicolumn{6}{|c|}{ CLASE SOCIAL } \\
\hline & & $\begin{array}{c}\text { CLASE } \\
\text { BAJA }\end{array}$ & $\begin{array}{c}\text { CLASE } \\
\text { MEDIA } \\
\text { BAJA }\end{array}$ & $\begin{array}{l}\text { CLASE } \\
\text { MEDIA }\end{array}$ & $\begin{array}{c}\text { CLASE } \\
\text { MEDIA } \\
\text { ALTA }\end{array}$ & $\begin{array}{l}\text { CLASE } \\
\text { ALTA }\end{array}$ & TOTAL \\
\hline \multirow{7}{*}{$\begin{array}{l}\text { Composición } \\
\text { social cuadra } \\
\text { o pasaje }\end{array}$} & $\begin{array}{l}\text { Solo } 1 \text { clase } \\
\text { social }\end{array}$ & 61,66 & 50,48 & 41,42 & 55,14 & 48,36 & 49,99 \\
\hline & 2 clases sociales & 23,82 & 24,79 & 33,01 & 35,47 & 31,43 & 30,23 \\
\hline & 3 clases sociales & 13,21 & 19,65 & 19,21 & 8,47 & 19,29 & 16,31 \\
\hline & 4 clases sociales & 1,1 & 4,2 & 2,77 & 0,78 & 0,88 & 2,35 \\
\hline & 5 clases sociales & - & 0,76 & 3,32 & 0,04 & 0,04 & 0,98 \\
\hline & $\begin{array}{l}\text { No sabe/No } \\
\text { responde }\end{array}$ & 0,22 & 0,12 & 0,27 & 0,1 & - & 0,14 \\
\hline & TOTAL & 100 & 100 & 100 & 100 & 100 & 100 \\
\hline
\end{tabular}

FUENTE ESTUdio DIS, 2008.

En el caso de Santiago, los sectores más homogéneos de la ciudad corresponden a amplias aglomeraciones de pobreza, como el norponiente y surponiente de la ciudad, y no a suburbios de altos ingresos. Estos sectores segregados a alta escala no son el resultado de que las personas escojan vivir ahí, sino consecuencia de que el subsidio habitacional que les entrega el Estado no les permite acceder a otra localización. Por otra parte, el sector que conocemos como "barrio alto", si bien concentra a la mayoría de las familias de altos ingresos de la ciudad, es bastante permeable a otros 
grupos sociales, lo que lo vuelve mucho más heterogéneo que los sectores pobres. Asimismo, hoy hay familias de altos ingresos que deciden irse a vivir a condominios cerrados en comunas tradicionalmente populares, como Peñalolén o Huechuraba, y más recientemente, Pudahuel y Puente Alto. Todo lo anterior refleja que quienes pueden elegir prefieren áreas más heterogéneas que las áreas donde viven quienes deben aceptar la localización de proyectos de vivienda social, que pueden pagar poco por el suelo. ${ }^{19}$

Estamos frente a una paradoja: en una sociedad que se autodeclara clasista como la chilena, quienes tienen más posibilidad de elegir viven en áreas más heterogéneas socialmente. Podría atribuirse ese resultado a la pulsión por penetrar las áreas por parte de hogares de menor condición social relativa, esto es, a los ánimos de movilidad social de los grupos "emergentes". Sin embargo, no parece una buena solución para la paradoja. En el caso de ciudades de Estados Unidos, donde la movilidad social opera con mucha fuerza, las clases medias y altas recurren a herramientas legales, como la norma de tamaño predial mínimo, para "defender" sus barrios de la penetración de los hogares de menores ingresos relativos. En Chile, en cambio, el uso de dichos instrumentos es mucho más acotado, y se da solo en sectores específicos de la ciudad. ¿Por qué estas herramientas no se utilizan con más fuerza, si también están disponibles aquí en Chile?

Asimismo, existen casos de barrios que presentan mezcla social, y que podrían catalogarse como experiencias exitosas. Así como hay temores frente a la integración, hemos encontrado una variedad de factores que la posibilitan en la práctica: hay hogares que privilegian el entorno natural del barrio por sobre la composición social del entorno (caso de estudio Las Condes); y hay familias que, teniendo recursos suficientes para mudarse al barrio alto, prefieren comprar una casa donde han vivido siempre, aunque ello signifique quedarse a vivir en medio de un entorno popular (caso de estudio Pudahuel). En ambos casos, la convivencia se ve posibilitada porque las decisiones de localización se basan en otros aspectos del barrio, distintos de su composición social. De este modo, queda en evidencia que la disposición a la integración residencial está lejos de afiliarse en forma coherente a lo que las personas hacen e, incluso, a lo que aparecen como dispuestas a hacer. Convergen un cúmulo de valoraciones, opiniones, actitudes y preferencias que pueden entrar en tensión entre sí e incluso ser contradictorias. A ello se suma la existencia de factores externos que influencian las decisiones de localización de los hogares, como la oferta inmobiliaria y las posibilidades económicas de cada hogar. De esta forma, la realidad de segregación observada en un momento dado dista mucho de reflejar la disposición a la integración residencial de las personas. Y tampoco refleja — debemos agregar- las posibilidades de mezcla social que contienen nuestras ciudades y sus barrios según reglas o claves que en gran medida desconocemos.

19 Con esto no argumentamos que los hogares de mayores ingresos escojan su localización porque prefieren la heterogeneidad, sino solo que pueden escoger localizaciones heterogéneas en la medida en que presenten además otros atributos que les parecen atractivos. 


\section{Desafíos de estudio y de políticas}

Destacamos aquí algunos desafíos académicos y de política pública que surgen de los resultados de nuestro estudio sobre segregación en ciudades chilenas.

\section{Desafíos de estudio}

Entre los temas necesarios de estudiar por sus alcances teóricos, proponemos los cuatro siguientes:

a) Miedos clasistas. En la ambivalencia entre formas verticalistas y ciudadanas de integración social merodean diversos "miedos clasistas", entre los que podríamos relevar el temor a ser confundido con el "otro" de menor condición social pero parecido a mí, y el rechazo a los "arribistas" sociales. Ambos temores aparecieron en nuestro trabajo de campo. Al primero lo hemos llamado "adolescencia urbana”, y da lugar a un intenso deseo de excluir de mi barrio a esos con los que puedo ser fácilmente confundido. El segundo, el fastidio con los “arribistas", revela resistencia a un fenómeno universal de la cultura moderna, la movilidad social. Como hemos señalado, solo desde el apego a la sociedad estamental y jerárquica tradicional se podría condenar el afán de movilidad social de las personas. Considerando los conflictos que pueden suscitar, ambos miedos deben ser estudiados empíricamente para saber en qué condiciones aparecen.

b) Nuestros pobres. En su esfuerzo por mantener el orden social en diferentes épocas y lugares, las elites diferencian a las personas pobres entre "meritorias" (de recibir ayuda social y apoyo de los demás) y quienes no lo son y deben ser considerados peligrosos o fuera del sistema social. Nuestros entrevistados de todas las clases sociales hicieron un distingo entre "nuestros pobres" y el resto de pobres, aunque con diferentes nomenclaturas. Necesitamos conocer más sobre esta "categorización dicotómica" (Tilly, 2000), porque de ella puede depender el apoyo que se logre para medidas orientadas a reducir la segregación de los grupos populares. ¿De qué factores depende esta categorización de pobres: de la cantidad de familias de menor condición social, su comuna de procedencia, orden de llegada a la comuna o sector, o de la existencia de vínculos funcionales o personales previos con residentes de clases superiores?

c) Asimetría de la segregación. Hemos destacado antes que los grupos medios y altos de la ciudad latinoamericana, al mismo tiempo que están fuertemente concentrados en el espacio, comparten sus áreas residenciales con el resto de grupos, lo que produce, como hecho característico, una asimetría entre las dos dimensiones objetivas de la segregación (alta concentración espacial del grupo y baja homogeneidad social del espacio). Una tarea de investigación es conocer cómo se organiza esta asimetría según escala geográfica. Por ejemplo, casi dos tercios de nuestros entrevistados en la encuesta declararon que prefieren vivir entre sus iguales, pero supimos mediante del estudio cualitativo que unas pocas cuadras más allá el sector podía ser socialmente diverso. 
d) Indiferencia tolerante. La forma específica de tolerancia entre grupos sociales, mezcla de empatía, indiferencia y temor, parece un fenómeno característico de la atmósfera psicológica de las ciudades, especialmente las grandes (Simmel, 1988). La indiferencia y el anonimato, lejos de ser negativos, son pilares de la vida pública (Sennett, 1976, p. 202). Hemos visto que esta mezcla de tolerancia e indiferencia toma formas y contenidos específicos en las ciudades estudiadas. Los entrevistados mencionan beneficios de la integración residencial en distintos planos: aprendizaje de valores para "los de arriba" y ventajas en lo funcional para los residentes de menores recursos. Asimismo, la mayoría estima que la cercanía espacial entre personas de distinta clase no necesariamente genera relaciones de amistad. Del otro lado, genera costos que podrían salvarse por medio de la política pública. Esto da cuenta de una visión no idealizada pero suficientemente positiva respecto de la integración residencial: no necesariamente produce lazos a nivel personal, pero sí genera beneficios concretos. Por una parte, permite identificar los costos y trabas asociados a la integración residencial y hacerlos foco de políticas; y por otro, puede erigirse en campo del aprendizaje social. Entonces, si la "indiferencia tolerante" es un recurso cultural donde construir el encuentro social y fortalecer el sentido de lo público, profundizar su conocimiento pasa a ser prioritario.

\section{Desafíos de políticas}

Respecto de los desafíos de política, destacamos los siguientes:

a) Los reparos especificos a la integración son también un campo de trabajo. En sociedades con cierto grado de tolerancia social y sentido de comunidad, comolas latinoamericanas, el rechazo al diferente toma razones específicas. No podría ser un rechazo total o inespecífico porque, al menos a nivel de discurso y valores, la cultura local tiende a ser cohesiva. La diferencia que hacen los residentes de ciudades chilenas entre buenos y malos pobres es parte de dicha precisión de los reparos. En lo práctico, el que el rechazo sea específico es una buena noticia para los urbanistas comprometidos con valores de integración y cohesión sociales. Las razones del rechazo que dieron nuestros entrevistados son todas modificables o evitables mediante proyectos de vivienda participativos y diseñados ad hoc. Entre los factores que se pueden cambiar están la cantidad de personas de menor condición social y la arquitectura de sus viviendas; y entre los factores que podrían evitarse, están las mezclas o adyacencias entre conjuntos residenciales de distinta condición social que pueden dar lugar a fenómenos de "adolescencia urbana” asociados con la defensa, por lo demás comprensible, de los proyectos de movilidad social de las personas.

b) El imperativo de la integración residencial sobre bases de equidad e implicancias sobre el rol del Estado. Como destacamos antes, integración social y clasismo son entendidos usualmente como realidades contrapuestas, aun cuando la práctica nos indica que pueden no ser excluyentes. El clasismo ha sido y sigue siendo en muchas sociedades el modo sobre el cual se afirma 
un tipo de integración que sustenta, a su vez, una particular atmósfera de cohesión social, propia de las sociedades tradicionales y premodernas. Ahora bien, el hecho de que se perciba la integración social como contrapuesta o contradictoria con el clasismo expresa un anhelo de integración cuya forma específica no se sostenga en la desigualdad; es decir, donde el ciudadano, con independencia de su clase social, pueda reivindicar sus derechos ante los demás — en este caso, su derecho a la ciudad-. Por lo tanto, si bien la integración social y el clasismo no son excluyentes en una sociedad en que la integración se plantea de modo vertical, los datos nos muestran que para los habitantes de las grandes ciudades de Chile este no es el modo de integración deseado. El opuesto de una sociedad clasista es una sociedad igualitaria, y es probablemente desde ese lugar - y parámetro - que se construye, al menos hoy y de manera creciente, la alta disposición a vivir cerca de personas de distinta condición social. Sin embargo, como veíamos antes, ese valor puede quedar refugiado y encapsulado en el espacio del anhelo, en el discurso, sin traducirse necesariamente en actitudes y acciones acordes. Dicho desfase entre palabra y acción, analizado desde la perspectiva de sus obstaculizadores, es a nuestro juicio lo que explica el fuerte respaldo a la posibilidad de que sea el Estado el que regule y haga posibles mayores niveles de integración social residencial. Cuando se trata del bien común, no son las personas - cada una por separado - quienes deben asegurarlo, sino que es el Estado, en tanto garante del bien común, el que tiene esa responsabilidad. Más allá de las posibilidades que abren en la materia los actuales instrumentos públicos, la política debiera tender hacia una integración en términos igualitarios - lo que paradójicamente podría lograrse aun a pesar de una base cultural clasista-, y minimizar y repartir equitativamente los costos individuales asociados al logro de este bien social. Ambos temas serán abordados a continuación.

c) Microbarrios, una forma práctica de responder a nuestros patrones culturales. Como hemos visto, la supuesta incompatibilidad entre integración social y clasismo que se percibe a primera vista, no sería tal. Si bien las personas quieren vivir entre iguales, basta con que los más cercanos lo sean, lo que da espacio a una cierta diversidad en el entorno más amplio. Por otra parte, el deseo de vivir con los iguales no es equivalente con el de excluir a los diferentes. Así, nuestro clasismo permitiría modelar una forma específica de habitar urbano con la configuración de "microbarrios" homogéneos combinados con la presencia de personas y grupos diferentes a partir de sus bordes. El desafío de política pública que esta idea acarrea sería identificar las características más específicas de la integración residencial que resultan aceptables para las distintas personas. Podemos señalar tres tareas en ese sentido: i) determinar la proporción mínima de hogares similares necesaria para que los integrantes de grupos sociales específicos se sientan cómodos en sus lugares de residencia, lo que, como contraparte, permitiría definir un margen de acción para la inclusión de una cierta cuota de alteridad; ii) identificar los niveles de "porosidad" o penetración por parte de "extraños" que son aceptados o que- 
ridos en los microbarrios, considerando que la seguridad objetiva y percibida debe ser buscada por las políticas de vivienda; y iii) definir los estándares y formas urbanas de los bordes o fronteras entre los distintos barrios, incluida la escala o tamaño de los microbarrios, que resulten "amigables" o favorables para una sana convivencia entre los residentes de los distintos microbarrios. Desde luego, la proporción mínima de los denominados “iguales" variará en función de elementos internos, como el ciclo de vida familiar, y externos, como las características de la vivienda y su localización o la distancia social con los vecinos de los barrios colindantes. Podrían, incluso, tomar forma situaciones de tradeoff entre estos elementos, como cuando las personas estén dispuestas a sacrificar una cierta cuota de homogeneidad social de su microbarrio por una mejor localización en la ciudad o, al revés, como cuando se está dispuesto a sacrificar accesibilidad física por una mayor distancia social con microbarrios cercanos, con el fin de evitar los conflictos que hemos reconocido como "adolescencia urbana". Estas consideraciones son válidas con independencia del grupo social del que se trate, no solo para los de mayor posición relativa. Debemos prestar especial atención a los aspectos sociales, de localización y diseño que hacen que alguien se sienta "como en casa".

d) Estilos de vida como fundamento de las comunidades barriales. Debe destacarse que la mencionada "igualdad" interna de los grupos no se juega solo en aspectos socioeconómicos, sino también en "estilos de vida". Las personas pueden estar más abiertas a la diversidad social cuando se comparten ciertas costumbres, valoraciones o formas de vivir. Algunas comunas ubicadas en las afueras de Santiago, tales como Colina, Calera de Tango, Talagante y Huechuraba, que conservan un cierto carácter rural o de entorno "natural", son un buen ejemplo de ello. Recientemente estos sectores han experimentado una paulatina transición hacia una mayor heterogeneidad social, gracias a la llegada de familias de mayor nivel socioeconómico, las cuales buscan más espacio y un entorno donde la presencia de la naturaleza sea más notoria. La diferencia en el nivel social de sus residentes no ha sido impedimento para que se haya fortalecido allí un sentido de comunidad. De este modo, los procesos de gentrificación, tenidos comúnmente como negativos en términos de equidad e integración social, en algunos casos podrían estar reflejando una importante disposición a la integración social.

e) Nivelar hacia arriba, clave para favorecer la integración residencial. Parece relevante trabajar la integración residencial interclases mediante una cierta cuota de transversalidad en el diseño de viviendas y los estándares urbanos, sobre el principio de "nivelación hacia arriba". Es lo que se está haciendo en el conjunto San Alberto de Casas Viejas, experiencia hasta ahora exitosa en términos de acomodar grupos sociales en un mismo barrio, aun grupos tan cercanos entre sí que podrían ser afectados por los problemas de la "adolescencia urbana". Si el diseño de las políticas de integración residencial fuera, más bien, el de microbarrios explicados antes, mucho podría hacerse para mejorar la acepta- 
ción de estos proyectos por vecinos circundantes de mejor condición social. La disposición de las viviendas económicas en condominios, el mantener el tamaño de los conjuntos dentro de ciertos límites, el apoyo de los municipios en la mantención de estos edificios y en la seguridad del entorno, entre otros, son elementos que contribuirían a la integración social del sector.

f) Obstáculos funcionales: su superación con proyectos estratégicos. Una fracción importante de los grupos más acomodados teme que el compartir el espacio residencial con clases más bajas pueda desembocar en una disminución en las plusvalías asociadas a su patrimonio. A pesar de que la mención de ese temor puede ser una forma solapada de clasismo, es innegable que el temor existe y que es bastante generalizado. Del otro lado, los grupos más pobres no disponen de oferta de vivienda a su alcance en entornos más heterogéneos socialmente, pese a mostrar mayor disposición a la integración que los otros grupos sociales. No obstante, el menoscabo a las plusvalías, como obstáculo a la integración residencial, no es un hecho suficientemente probado. La promoción de ciertos proyectos de carácter estratégico podría contribuir mucho a las políticas de integración, como en el caso de los que, focalizados en grupos medios o altos menos temerosos con relación a las plusvalías, se erigieran en ejemplos demostrativos de que la mezcla no necesariamente erosiona el valor de las propiedades. Una medida posible sería la subvención de arriendos a parejas jóvenes sin hijos en conjuntos integrados socialmente mientras se ahorra para la vivienda propia.

g) El rol de las regulaciones estatales en materia de integración social: fundamento en el bien común. Existen ámbitos en los cuales un determinado beneficio social es claro y aceptado por todos y, sin embargo, es necesario ahondar en un imperativo que regule una conducta coherente con dicha valoración que de modo individual no se vería asegurado. Este es el ámbito de la filosofía política y del derecho que la ética ha señalado como "bien común”. En otras palabras, el considerar el bien común como legítimo o deseable no es sinónimo de estar dispuesto a enfrentar individualmente los costos asociados a su persecución. Un ejemplo que es claro para dar cuenta de esta situación es el cobro de impuestos. Estos deben operar bajo una cláusula de obligatoriedad. Vale decir, libremente sería difícil esperar que cada uno de los habitantes de una nación pagara los impuestos que van a cubrir aspectos que socialmente son valorados (salud, educación, infraestructura pública, etcétera) y, sin embargo, ello no es indicativo de un desacuerdo con la necesidad del cobro de impuestos. Lo crítico es la garantía que el Estado pueda dar a cada cual respecto de que el cobro de impuestos se aplica a todos a quienes corresponda. Cuando el costo asociado a alcanzar ese bien común se encuentra adecuadamente distribuido, es aceptado. Se asume el costo, en pos de un beneficio mayor, en la medida que su distribución sea pareja (y en proporción) para toda la población. Lo mismo podríamos argumentar respecto de la alta disposición a la integración social, y al hecho que se pretenda que dicha integración se articule bajo cláusulas 
de igualdad y no de clasismo. En resumidas cuentas, si por una parte tenemos que los habitantes de las grandes ciudades perciben un claro beneficio de la integración social residencial y, por otra, que esta no es valorada en "sí misma" sino que desde una perspectiva que apunta claramente hacia la justicia, entonces podríamos apostar por abrir la discusión acerca del rol del Estado en la provisión de este bien social. La percepción de beneficios de la integración no se traduce fácilmente en acciones cuando éstas penden de las opciones individuales; ${ }^{20} \mathrm{y}$, sin embargo, una mayor integración sería aceptada si ella fuera regulada desde el Estado, en la medida en que entregaría garantías sobre la distribución de las cargas y los beneficios de una mayor integración social.Laacción delEstadoen estos temas, lejos desercontradictoriacon las preferencias de las personas, permitiría lograr un escenario más congruente con las valoraciones de las personas y el tipo de ciudades en que quieren vivir, al mismo tiempo que lograría reducir sus temores cotidianos y aprehensiones económicas. En el plano de la vivienda social, la intervención pública podría tomar la forma, por ejemplo, de normas sobre cuotas mínimas de vivienda social a nivel comunal o, en su defecto, de contribuciones compensatorias para saltárselas. En cualquiera de esas alternativas, esta acción del Estado ayudaría a reforzar la legitimidad social de la política, al fortalecer el reconocimiento de la integración social como un valor de la sociedad chilena. En términos prácticos, este tipo de medidas contribuiría, a su vez, a aumentar la disponibilidad de suelo para aquellos grupos con menor capacidad de pago. OEURE

\section{Referencias bibliográficas}

Bauder, H. (2001). You're good with your hands, why don't you become an auto mechanic: Neighborhood context, institutions and career development. International Journal of Urban Regional Research, 25(3), 593-608. doi: 10.1111/1468-2427.00331

Bauman, Z. (2000). Trabajo, consumismo y nuevos pobres. Barcelona: Gedisa.

Bauman, Z. (2001). En busca de la política. Buenos Aires: Fondo de Cultura Económica.

Bauman, Z. (2010). La cultura como praxis (2 ${ }^{\mathrm{a}} \mathrm{ed}$.). Barcelona: Paidós.

Bengoa, J. (1996). La comunidad perdida. Ensayos sobre identidad y cultura: los desafíos de la modernización en Chile. Santiago: Ediciones SUR. Disponible en http://www.sitiosur.cl/r. php?id=83

Bobo, L. \& Zubrinsky, C. (1996). Attitudes on residential integration: Perceived status differences, mere in-group preference, or racial prejudice? Social Forces, 74(3), 883-909 [University of North Carolina Press]. En: http://www.jstor.org/stable/2580385

Briggs, X., Darden, J. \& Aidala, A. (1999). In the wake of desegregation. Early impacts of scattered-site public housing on neighborhoods in Yonkers, New York. Journal of the American Planning Association, 65(1), 27-49. En http://www.huduser.org/publications/pdf/wake.pdf

Cáceres, G. \& Sabatini, F. (2007). Suburbanización y segregación urbana en el Chile decimonónico:

20 Esto se desprende de los análisis de T. Schelling, quien nos muestra cómo la suma de preferencias individuales, no necesariamente a nivel agregado, produce el resultado de la decisión tomada a nivel individual. 
Hipótesis sobre la formación histórica del Gran Valparaíso. En J. Valenzuela (Ed.), Historias urbanas. Homenaje a Armando de Ramón (pp. 93-121). Santiago: Ediciones Universidad Católica de Chile.

Clark, W. (1986). Residential segregation in American cities: A review and interpretation. Population Research and Policy Review, 5(2), 95-127. doi: 10.1007/BF00137176

Cummings, P. \& Landis, J. (1993). Relationships between affordable housing developments and neighboring property values. An analysis of BRIDGE Housing Corporation developments in the San Francisco Bay Area. Berkeley, CA: University of California at Berkeley, Institute of Urban \& Regional Development. En http:/ / ebookbrowse.com/relationships-between-affordablehousing-developments-and-neighboring-property-values-pdf-d90631244

Dureau, F. \& Salas, A. (2010). Las diferentes expresiones del proceso de segregación en Bogotá. En S. Jaramillo (Ed.), Bogotá en el cambio de siglo: Promesas y realidades (pp. 195-220). Quito: Organización Latinoamericana y del Caribe de Centros Históricos (Olacchi).

Fishman, R. (1987). Bourgeois utopias. Nueva York: Basic Books.

Flores, C. (2006). Consecuencias de la segregación residencial: Teoría y métodos. En J. M. Cunha (Comp.), Metrópoles paulistas: População, vulnerabilidade e segregação (pp 197-230). Campinas: Universidade Estadual de Campinas (Unicamp).

Galster, C. \& Killen, S. (1995) The geography of metropolitan opportunity: a reconnaissance and conceptual framework. Housing Policy Debate, 6(1), 7-43. doi:10.1080/10511482.1995 .9521180

Goetz, E., Lam, H. \& Heitlinger, A. (1996). There goes the neighborhood? Subsidized housing in urban neighborhoods. CURA Reporter, 26(1), 1-6 [Center for Urban and Regional Affairs, University of Minnesota]. En http://www.cura.umn.edu/sites/cura.advantagelabs.com/ files/publications/26-1-goetz-heitlinger.pdf

Gornstein, A. \& Verrilli, A. (2006). Mixed income housing in the suburbs: Lessons from Massachusetts. En: www.chapa.org/pdf/MixedIncomeReport.pdf

Gramsci, A. (1985 [1932-1933]). Introducción al estudio de la filosofia (Cuadernos de la Cárcel 11). Barcelona: Crítica.

Green, R. K., Malpezzi, S. \& Seah, K.-Y. (2002). Low-income housing tax credit housing developments and property values. Madison, WI: Center for Urban Land Economics Research, University of Wisconsin.

Harvey, D. (2011). The enigma of capital and the crises of capitalism. Londres: Profile Books Ltd.

Jenks, C. \& Mayer, S. (1990). The consequences of growing up in a poor neighborhood. En L. Lynn \& M. McGeary (Eds.), Inner-city poverty in the United States (pp. 111-186). Washington, D.C.: National Academy Press.

Larrañaga, O. \& Sanhueza, C. (2008). Las consecuencias de la segregación residencial para los más pobres. Santiago: Observatorio Económico, Facultad de Economía y Negocios, Universidad Alberto Hurtado.

Massey, D. \& Denton, N. (1988). The dimensions of residential segregation. Social Forces, 67(2), 281315. En :http://www.jstor.org/stable/2579183

Maxfield Research, Inc. (2000). A study of the relationship between affordable family rental housing and home values in the twin cities [Final Report]. Minneapolis, MN: Family Housing Fund. En http://www.fhfund.org/_dnld/reports/Property\%20Values_Full\%20Report.pdf 
Mollenkopf, J. H. \& Castells, M (1991). Dual city: Restructuring New York. Nueva York: Russel Sage Foundation.

Musterd, S. (2005). Housing mix, social mix, and social opportunities. Urban Affairs Review, 40(6), 761-790. doi: $10.1177 / 1078087405276006$

Myerson, D. L. (2003), Mixed-income housing. Myth and fact. Myth and Fact Series 5. Washington, D.C.: ULI-the Urban Land Institute.

National Association of Home Builders - Economics, Mortgage Finance, and Housing Policy Division (1999). Producing affordable housing: Partnerships for profit. Washington, D.C.: Home Builder Press.

Orfield, M. (1997). Metropolitics. A regional agenda for community and stability. Washington, D.C.: Brookings Institution Press.

Ortiz, R. (1980). A Consciência Fragmentada. Brasil: Paz e Terra.

Parsons, T. (1968 [1937]). The structure of social action. Nueva York: Free Press.

Pollakoswki, H.; Ritchay, D. \& Weinrobe, Z. (2005). Effects of mixed-income, multifamily rental housing developments on single-family housing values. Cambridge, MA: Center for Real State, Massachusetts Institute of Technology (MIT).

Popkin, S. (2006). The HOPE VI Program: What has happened to the residents? En L. Bennett, J. Smith, \& P. Wright (Eds.), Where are poor people to live. Transforming public housing communities (pp. 68-90). Nueva York y Londres: M. E. Sharpe.

Portes, A. \& Hoffman, K. (2003). Las estructuras de clase en América Latina: Composición y cambios durante la época neoliberal. [Documento 68 de la División de Desarrollo Social, Serie Políticas Sociales]. Santiago: Comisión Económica para América Latina y el Caribe (Cepal).

ProUrbana (Programa de Apoyo a las Políticas Urbanas y de Suelo en Chile, Pontificia Universidad Católica de Chile). (2007). Políticas de suelo para la integración social [Ciclo de Reuniones, 5 a publicación]. Santiago: ProUrbana/Lincoln Institute of Land Policy. En http://politicaspublicas.uc.cl/media/publicaciones/pdf/20100617121024.pdf

ProUrbana (Programa de Apoyo a las Políticas Urbanas y de Suelo en Chile, Pontificia Universidad Católica de Chile) \& Observatorio Social de la Universidad Alberto Hurtado (OSUAH). (2006). Preferencias de Regulación Urbana en Chile. Programa de Apoyo a las Políticas Urbanas y de Suelo, Políticas Públicas Universidad Católica de Chile; y Observatorio Social de la Universidad Alberto Hurtado.

Roa, A. (1997). Chile y Estados Unidos: Sentido histórico de dos pueblos. Santiago: Dolmen Ediciones.

Roberts, B. \& Wilson, R. (2009a). Residential segregation and governance: An overview. En B. Roberts \& R. Wilson (Eds.), Urban segregation and governance in the Americas (pp. 1-20). Nueva York: Palgrave Macmillan.

Roberts, B. \& Wilson, R. (2009b). Spatial differentiation, inequality and urban policy: The findings. En B. Roberts \& R. Wilson (Eds.), Urban segregation and governance in the Americas (pp. 205-222). Nueva York: Palgrave Macmillan.

Rosenbaum, J. (1995). Changing the geography of opportunity by expanding residential choice: Lessons from the Gautreaux program. Housing Policy Debate, 6(1), 231-269. En http://www. ciatrans.net/FannieMae_Gautreaux_Lessons.pdf

Sabatini, F. (1997). Liberalización de los mercados de suelo y segregación social en las ciudades latinoamericanas: el caso de Santiago, Chile. [Ponencia presentada ante el XX International Congress of the 
Latin American Studies Association, LASA, Guadalajara, México, abril 1997]. Santiago: Documentos del Instituto de Estudios Urbanos, P. Universidad Católica de Chile. Serie Azul n. 14.

Sabatini, F. \& Brain, I. (2008). La segregación, los guetos y la integración social urbana: mitos y claves. EURE, 34(103), 5-26. doi: 10.4067/S0250-71612008000300001

Sabatini, F. \& Cáceres, G. (2004). Los barrios cerrados y la ruptura del patrón tradicional de segregación en las ciudades latinoamericanas: el caso de Santiago de Chile. En G. Cáceres \& F. Sabatini (Eds.), Los barrios cerrados en Santiago de Chile: Entre la exclusión y la integración social (pp. 9-44). Santiago: Instituto de Geografía, Pontificia Universidad Católica de Chile.

Sabatini, F.; Cáceres, G. \& Cerda, J. (2001). Segregación residencial en las principales ciudades chilenas: tendencias de las tres últimas décadas y posibles cursos de acción. EURE, 27(82), 21-42, doi: 10.4067/S0250-71612001008200002

Sabatini, F., Vásquez, H., Robles, S., \& Rasse, A. (2010). Gentrificación sin expulsión, fuerza de transformación de las ciudades latinoamericanas: datos e interpretación para Santiago. En F. Sabatini, R. Salcedo, G. Wormald \& G. Cáceres (Eds), Tendencias de la segregación en las principales ciudades chilenas. Análisis censal 1982-200 (pp. 165-184). Santiago: Instituto Nacional de Estadísticas y Pontificia Universidad Católica de Chile.

Sabatini, F.; Wormald, G. \& Salcedo, R. (2008). Informe final de resultados del estudio "Barrios en crisis y barrios exitosos producidos por la politica de vivienda social en Chile". Santiago: Conicyt, Programa Anillos de Investigación en Ciencias Sociales.

Sampson, R. \& Raudenbush, S. (2004). Seeing disorder: Neighborhood stigma and the social construction of 'Broken Windows'. Social Psychology Quarterly, 67(4), 319-342. doi: $10.1177 / 019027250406700401$

Sennett, R. (1970). The uses of disorder: Personal identity and city life. Nueva York y Londres: Norton. Sennett, R. (1976). El declive del hombre público. Barcelona: Península.

Siegel, J. (1998). The house next door. Baltimore: Innovative Housing Institute.

Sierralta, C. (2010). Efectos sociales de la segregación residencial. Los jóvenes de Santiago de Chile (19922002). México: Infonavit-Redalyc.

Simmel, G. (1988 [1903]). La metrópolis y la vida mental. En M. Bassols, R. Donoso, A. Massolo \& A. Méndez (Comps.), Antología de Sociología Urbana (pp. 47-61). México: Universidad Nacional Autónoma de México (UNAM).

Simmel, G. (2000 [1918]) El conflicto de la cultura moderna. Revista Española de Investigaciones Sociológicas, 89, 315-330. En http://redalyc.uaemex.mx/src/inicio/ArtPdfRed. jsp?iCve $=99717889014$

Tilly, Ch. (2000). La desigualdad persistente. Buenos Aires: Manantial.

Urban Land Institute (2003). Mixed-income housing. Myth and fact. Washington, D.D.: Autor. En: http://www.uli.org/ResearchAndPublications/Reports/ /media/Documents/ResearchAndPublications/Reports/Affordable\%20Housing/MixedIncome.ashx

Véliz, C. (1970). Introducción. En C. Véliz (Ed.), El conformismo en América Latina. Santiago: Editorial Universitaria.

Watt, I. (1963). The rise of the novel: Studies in Defoe, Richardson, and Fielding. Harmondsworth: Penguin. Wilkins, S. (2002). Early conclusions from The Mixed-Income Demonstration Program: Reaching extremely low-income families in mixed-income settings. En http://www.nw.org/network/pubs/ studies/documents/ MixedIncomerReport2002.pdf 
Wilson, J. (1987). The truly disadvantaged. Chicago, IL: The University of Chicago Press.

Wormald, G. (2007). ¿Cómo debe entenderse la integración social en la ciudad? [Ciclo de Reuniones políticas de suelo para la integración social, VI Sesión]. Santiago: ProUrbana.

Zamorano, R. (2008). Modernidad, sociedad y constitucionalismo en América Latina. Cuestiones Constitucionales, 19 [Revista Mexicana de Derecho Constitucional], 237-282. En http:// www.revistas.unam.mx/index.php/cuc/article/view/2234

Zeitlin, M. \& Ratcliff, R. (1988). Landlords and capitalists. The dominant class of Chile. Princeton, NJ: Princeton University Press.

Zhang, Y. \& Weismann, G. (2006). Public housing's Cinderella: policy dynamics of HOPE VI in the mid 1990s. En L. Bennett, J. Smith \& P. Wright), Where are poor people to live. Transforming public housing communities (pp. 41-67). Armonk, NY: M. E. Sharpe. 